\title{
Target-based therapies in breast cancer: current status and future perspectives
}

\author{
Nicola Normanno ${ }^{1,2}$, Alessandro Morabito ${ }^{3}$, Antonella De Luca ${ }^{1}$, Maria \\ Carmela Piccirillo ${ }^{3}$, Marianna Gallo ${ }^{1}$, Monica $R^{2}$ Maiello ${ }^{1}$ and Francesco Perrone ${ }^{3}$
}

\footnotetext{
${ }^{1}$ Cell Biology and Biotherapy Unit, INT-Fondazione Pascale, 80131 Naples, Italy

${ }^{2}$ Pharmacogenomic Laboratory, Centro di Ricerche Oncologiche di Mercogliano - CROM, Mercogliano (AV), 83013 Italy

${ }^{3}$ Clinical Trials Unit, INT-Fondazione Pascale, Naples, 80101 Italy
}

(Correspondence should be addressed to N Normanno at Cell Biology and Preclinical Models Unit, INT-Fondazione Pascale; Email: nicnorm@yahoo.com)

\begin{abstract}
Identification of molecular alterations in key proteins involved in breast cancer cell proliferation and survival resulted in the development of a new treatment strategy with target-based agents. The anti-ErbB-2 monoclonal antibody (mAb) trastuzumab and the dual epidermal growth factor receptor/ErbB-2 tyrosine kinase inhibitor lapatinib are effective in patients with breast cancer that overexpresses ErbB-2. The anti-vascular endothelial growth factor-A mAb bevacizumab is approved in combination with taxanes for treatment of unselected patients with metastatic breast cancer. In addition, preclinical data suggest that signaling inhibitors can prevent or overcome resistance to endocrine therapy in estrogen receptor positive $(E R+)$ breast cancer. However, the majority of signaling inhibitors explored in breast cancer patients has shown little activity, at least when used as monotherapy; and the results of clinical trials in ER + breast cancer of combinations of signaling inhibitors and endocrine therapies are rather disappointing. Negative findings are likely due to mechanisms of intrinsic or acquired resistance to target-based agents. Breast carcinoma is a complex and heterogeneous disease and several different molecular alterations are involved in its pathogenesis and progression. The redundancy of oncogenic pathways activated in cancer cells, the heterogeneity of the mechanisms of resistance, and the plasticity of tumor cells that are capable to adapt to different growth conditions, significantly hamper the efficacy of each signaling inhibitor in breast cancer. Therefore, a comprehensive approach that takes into account the complexity of the disease is definitely required to improve the efficacy of target-based therapy in breast cancer.
\end{abstract}

Endocrine-Related Cancer (2009) 16 675-702

\section{Introduction}

The identification of mechanisms that regulate proliferation and survival of tumor cells is leading to the development of novel therapeutic approaches. To date, several agents specific for molecular targets amplified or overexpressed in cancer cells have been generated. Owing to their high selectivity, these drugs generally have fewer side effects as compared with most conventional chemotherapeutic agents, and can be combined with conventional therapies to improve the response to treatment without a major increase in side effects.

Breast cancer is a complex and heterogeneous disease. The development of high throughput technologies has recently underscored such complexity by revealing the existence of different subtypes of breast carcinoma that are characterized by specific gene expression profiles (Sorlie et al. 2001). As a matter of fact, endocrine treatment of estrogen receptor positive $(\mathrm{ER}+)$ breast cancer with tamoxifen, and later on with aromatase inhibitors and fulvestrant, has been the first target-based therapeutic strategy in oncology (Normanno et al. 2005c,d). The anti-ErbB-2 monoclonal antibody $(\mathrm{mAb})$ trastuzumab and, more recently, the dual EGFR/HER2 tyrosine kinase inhibitor (TKI) lapatinib have shown significant clinical activity in patients with breast cancer that overexpresses the ErbB-2 receptor (Nanda 2007). However, some other 
innovative approaches, including drugs directed against angiogenesis, have been developed in unselected patients because of the lack of information on the role of the specific signal transduction pathways in the pathogenesis and progression of the different subtypes of breast cancer.

This review aims to provide an overview on current status and future perspectives of target-based therapies in breast cancer. Before discussing the preclinical and clinical findings obtained with these agents, we will briefly describe the main signaling pathways against which target-based agents are being developed in breast cancer.

\section{Molecular targets in breast cancer}

The growth and survival of breast cancer cells is sustained by different growth factor receptor-driven signaling pathways (Fig. 1). Among these, the role of the epidermal growth factor receptor (EGFR) family of tyrosine kinase receptors in the pathogenesis of breast cancer has long been established. The EGFR family includes four different receptor tyrosine kinases: EGFR (ErbB-1), ErbB-2 (HER2), ErbB-3, and ErbB-4 (Normanno et al. 2005a). Each of these proteins possesses an extracellular ligand-binding domain, a single hydrophobic transmembrane domain and a cytoplasmic tyrosine kinase-containing domain (Olayioye et al. 2000). The receptors of the ErbB family are activated following binding to peptide growth factors of the EGF-family that induce formation of either homo- or hetero-dimers. Dimer formation precedes the activation of the kinase that leads to an auto- and trans-phosphorylation in tyrosine residues (Olayioye et al. 2000).

Expression of the EGFR has been reported in 14-91\% of breast carcinomas (Salomon et al. 1995, Normanno et al. 2003). Overexpression of the EGFR has been linked to a more aggressive breast tumor phenotype and to poorer patient prognosis, although the results are discordant (Salomon et al. 1995, Normanno et al. 2003, 2005a,c). More recently, it has been shown that the 'triple negative' breast cancer subtype expresses the EGFR at higher frequency as compared with other subtypes (Reis-Filho \& Tutt 2008). Expression of ErbB-2 is more restricted and occurs in $\sim 20-30 \%$ of human primary breast carcinomas. High levels of expression of this receptor generally correlate with poor prognosis, although mixed results have also been reported (Salomon et al. 1995, Normanno et al. 2003, 2005a). ErbB-3 and ErbB-4 expression has been demonstrated to occur at high frequency in breast cancer patients (Salomon et al. 1995, Normanno et al. 2003, 2005a).

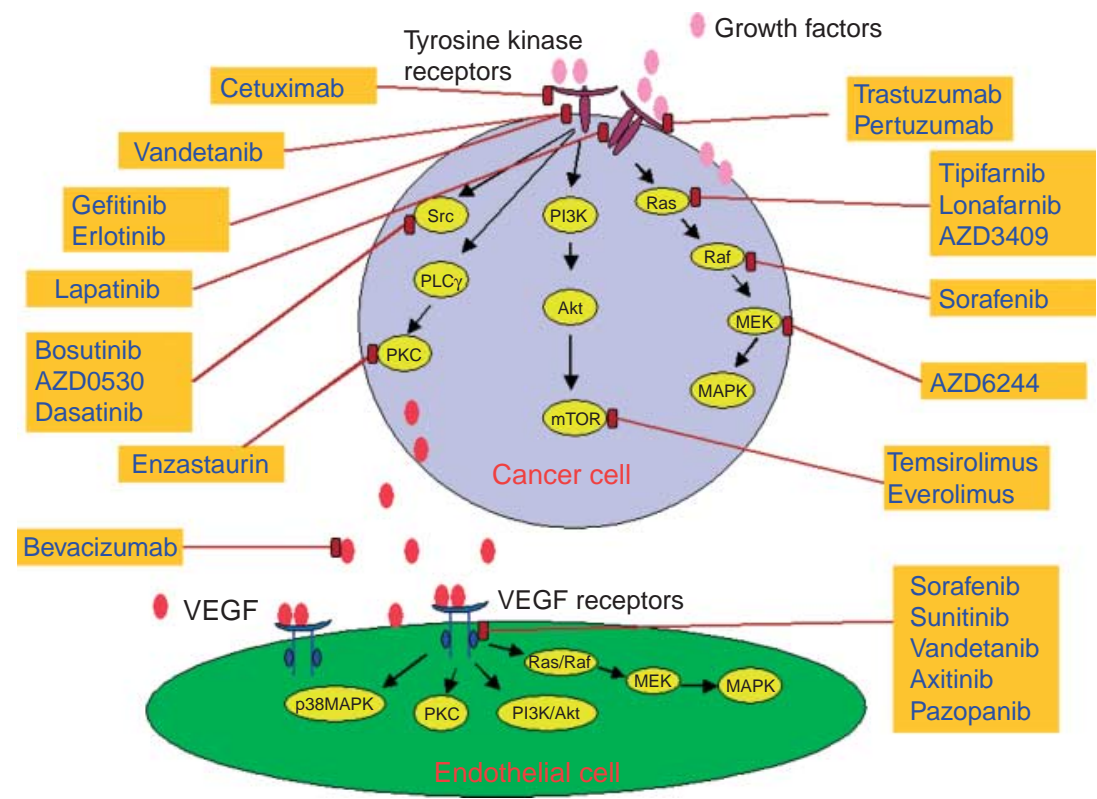

Figure 1 Growth factor receptor-driven signaling pathways and target-based agents in clinical development in breast cancer. Binding of specific ligands that are produced by either tumor cells or by surrounding stromal cells activate growth factor receptors expressed by tumor cells, including ErbB receptors. The activated tyrosine kinase receptors are able to interact with signaling molecules that regulate different mechanisms involved in tumor pathogenesis and progression, such as proliferation, survival, invasion, and angiogenesis. VEGF receptors mediate the downstream effects of VEGF, which leads to the activation of intracellular signaling transduction pathways that are involved in endothelial cell proliferation, migration, and survival. 
Co-expression of two or more ErbB receptors has been frequently found in breast carcinoma (Normanno et al. 2003, 2005a,c). Expression of phosphorylated ErbB-2 or co-expression of ErbB-2 and EGFR was associated with shorter survival in breast cancer patients (DiGiovanna et al. 2005). Similarly, co-expression of EGFR, ErbB-2, and ErbB-3 had negative synergistic effect on patient outcome, independent of tumor size or lymph node status (Wiseman et al. 2005). The redundancy of expression is not limited to the ErbB receptors but it also occurs for EGF-like peptides, such as transforming growth factor- $\alpha$ (TGF- $\alpha$ ), amphiregulin and/or neuregulin(s) that are expressed at high frequency in primary breast tumors (Normanno et al. 2001). Finally, ErbB receptors and EGF-like peptides are generally expressed at higher levels in ER - breast carcinomas as compared with ER + tumors (Normanno et al. 2001). However, a progressive increase in the levels of expression and activation of EGFR and ErbB-2 has been described in ER + breast cancer cells that develop resistance to anti-estrogen therapy (Nicholson et al. 2004, Normanno et al. 2005c,d).

Following ligand-induced activation, the tyrosinephosphorylated receptors become able to interact with adaptor proteins that couple the receptors to intracellular signaling pathways (Olayioye et al. 2000). The ErbB receptors can activate different intracellular signaling cascades, including the phosphatidylinositol 3-kinase (PI3K)/v-akt murine thymoma viral oncogene homolog 1 (AKT) and the Ras/Raf/mitogen-activated protein kinase kinase (MEK)/mitogen-activated protein kinase (MAPK) pathways. However, these pathways might also be activated in an ErbB-independent manner, by molecular alterations of signaling proteins or by tyrosine kinase receptors other than the ErbB receptors.

The Ras/Raf/MEK/MAPK pathway is activated by tyrosine kinase receptors through either Grb2 and Sos or Shc adaptor proteins (Downward 2003). In turn, Ras activates Raf that, through intermediate steps, leads to phosphorylation of p42/44 MAPK (Downward 2003). Several studies have demonstrated that MAPK signaling promotes proliferation and survival of breast cancer cells (Dunn et al. 2005). Furthermore, activation of MAPK signaling has been associated with resistance to both EGFR targeting agents and endocrine therapy in breast carcinoma (Normanno et al. 2005c,d, 2006). Mutations of Ras and B-Raf genes that lead to abnormal activation of this pathway have been rarely identified in human primary breast cancer (Bos 1989). Surprisingly, Ras mutations have been recently described in $18 \%$ of human breast cancer cell lines (Hollestelle et al. 2007). Similarly, B-Raf mutations have been identified in $10 \%$ of breast cancer cell lines (Hollestelle et al. 2007). These findings suggest that Ras or Raf mutations might occur in a late stage of breast tumor progression, and that they might provide a growth advantage to clones of cells that can generate continuous cell lines.

The protein kinase $\mathrm{C}$ (PKC) family consists of at least 12 serine/threonine kinases that mediate intracellular signaling (reviewed in Mackay \& Twelves 2007). Phosphorylation of tyrosine kinase receptors, such as the EGFR and the vascular endothelial growth factor receptor (VEGFR), induces activation of PKC through phospholipase $\mathrm{C} \gamma$. The downstream events following PKC activation are little understood, although both the MEK/MAPK and the PI3K/AKT pathways are thought to have an important role. Activated PKC phosphorylates and activates a range of kinases. Among these, the serine/threonine kinase glycogen synthase kinase $3 \beta$ (GSK3 $\beta$ ) is involved in metabolism, development, and apoptosis and is also one of the main targets of the PI3K/AKT pathway. Furthermore, PKCs $\alpha, \beta$, and $\eta$ directly phosphorylate AKT. It has been suggested that PKC plays a role in the pathogenesis of breast cancer. The total levels of PKC enzymatic activity are elevated in malignant breast tumors when compared with normal breast tissue (O'Brian et al. 1989, Gordge et al. 1996). The PKC $\beta$ isoform is known to be an important mediator of angiogenesis and represents an emerging target in breast cancer (Sledge \& Gokmen-Polar 2006).

The PI3K/AKT pathway regulates different functions that play an important role in tumor progression, such as cell growth, survival, invasion, and migration (Liu et al. 2007). A mechanism for abnormal PI $3 K$ activation in cancer is through somatic mutations in the genes that encode positive and negative effectors of this pathway (Crowder \& Ellis 2005). Loss of expression or functional loss of PTEN, a powerful negative regulator of PI3K signaling, occurs in different cancer types and results in constitutive AKT activation (Ali et al. 1999, Vivanco \& Sawyers 2002). The frequency of PTEN mutations in human primary breast carcinoma is $\sim 6 \%$ (Forbes et al. 2006). More recently, activating mutations of the PIK3CA gene, which encodes for the PI3K p110 catalytic subunit, were found in $\sim 25 \%$ of primary breast tumors (Karakas et al. 2006).

One of the main targets of the PI3K/AKT cascade is the serine/threonine kinase mammalian target of rapamycin (mTOR), which belongs to the phosphoinositide kinase-related kinase family (Liu et al. 2007). Activation of mTOR, in turn, regulates translation initiation through activation of ribosomal p70S6 kinase (S6K1) and inactivation of the 4E-BP1 
suppressor protein (Liu et al. 2007). The RPS6KB1 gene, which encodes S6K1, is amplified in $\sim 10 \%$ of breast cancer (Sinclair et al. 2003). RPS6KB1 gene amplification correlates with ErbB-2 overexpression in breast tumors, possibly due to coamplification of RPS6KB1 with ErbB-2 (Sinclair et al. 2003).

Increasing evidence suggests a role of Src in breast cancer progression. Src is the prototype of a large family of nonreceptor protein tyrosine kinases, known as the Src family kinases (Yeatman 2004). Src can be activated by cytoplasmic proteins, such as focal adhesion kinase (FAK) or its molecular partner Crkassociated substrate, which is involved in integrin signaling, and by ligand-activated tyrosine kinases of cell surface receptors, including EGFR and ErbB-2 (Yeatman 2004). Src is able to activate several different intracellular signaling pathways, including the PI3K/AKT and the Ras/Raf/MAPK pathways. In human mammary carcinomas a Src kinase activity 4- to 20-fold higher than normal tissues has been found (Irby \& Yeatman 2000). A cooperation between Src and EGFR in breast cancer tumorigenesis has also been hypothesized (Maa et al. 1995, Dimri et al. 2007). Finally, Src plays an important role in epithelial to mesenchymal transition (EMT) that enhances the metastatic potential of tumor cells (Larue \& Bellacosa 2005).

Angiogenesis, the formation of new blood vessels from the existing vasculature, is essential for the growth of the primary tumor and for the formation of metastasis. One of the key molecules responsible for the regulation of tumor-associated neoangiogenesis is VEGF-A (from now referred as VEGF), although additional growth factors, such as interleukin-8, basic fibroblast growth factor and the EGFR ligands EGF and TGF- $\alpha$, might play a role in this phenomenon (Ferrara \& Kerbel 2005, Kowanetz \& Ferrara 2006). VEGF binds two related receptor tyrosine kinases: VEGFR-1 (Flt-1) and VEGFR-2 (Flk/KDR; Ferrara \& Kerbel 2005). VEGFR-1 is a potent, positive regulator of physiologic and developmental angiogenesis and is involved in endothelial cell migration and differentiation. VEGFR-2 mediates the majority of the downstream effects of VEGF, including vascular permeability, endothelial cell proliferation, invasion, migration, and survival. A third member of the VEGFR family, VEGFR-3, is involved in lymphangiogenesis. Increased VEGF expression has been observed in breast cancer patients (Schneider \& Miller 2005). Several studies have suggested that a correlation might exist between high VEGF expression and poor clinical outcome and lack of response to tamoxifen and chemotherapy in patients with advanced breast cancer (Schneider \& Miller 2005).

\section{Target-based agents in breast cancer}

The target-based agents that have been approved for therapy of breast cancer patients or that entered clinical development can be divided in three large groups:

1) agents directed against specific subtypes of breast cancer, such as anti-estrogen (that will not be discussed in this paper) and anti-ErbB-2 compounds;

2) drugs targeting the tumor microenvironment such as anti-angiogenic agents that are potentially active in all the different subtypes of breast carcinoma;

3) inhibitors of specific signaling pathways, for the majority of which a role in the treatment of specific subtypes of breast carcinoma has not been demonstrated yet.

\section{Anti-ErbB-2 drugs}

In the past two decades several agents directed against the ErbB receptors have been developed. They include mAbs that bind the extracellular domain of the target receptor, and small molecule TKIs, which directly inhibit tyrosine kinase phosphorylation by physical interaction with either the ATP and/or the enzyme substrate binding site (Table 1; Normanno et al. 2003).

\section{Trastuzumab}

Trastuzumab is a humanized $\mathrm{mAb}$ with high specificity for ErbB-2 that showed moderate clinical activity in first or second-line treatment of ErbB-2 positive metastatic breast cancer as single agent (Baselga et al. 1999, Cobleigh et al. 1999, Vogel et al. 2002) or in combination with chemotherapy (reviewed in Demonty et al. (2007)). The addition of trastuzumab to first-line chemotherapy (either paclitaxel or anthracycline based) significantly improved response rate, time to progression (TTP), and overall survival in a pivotal randomized phase III trial (Slamon et al. 2001; Table 2). The benefit of combination treatment was also confirmed by a quality of life analysis (Osoba et al. 2002). The high rate of cardiotoxicity in the subgroup of patients treated concurrently with anthracyclines limited the use of this latter combination in clinical practice.

Two randomized phase II studies confirmed the efficacy and the safety of the combination of trastuzumab with weekly paclitaxel or 3-weekly docetaxel (Marty et al. 2005, Gasparini et al. 2007). However, due to an increasing use of taxanes in the 
Table 1 Target-based agents in clinical development in breast cancer

\begin{tabular}{lll}
\hline Target & Drug & Other sites of action \\
\hline EGFR & Gefitinib & None \\
& Erlotinib & ErbB-2 \\
Lapatinib & ErbB-2 \\
ErbB-2 & Trastuzumab & None \\
& Pertuzumab & None \\
VEGF-A & Lapatinib & EGFR \\
VEGFR & Bevacizumab & None \\
& Sorafenib & VEGFR-2, VEGFR-3, PDGFR- $\beta$, KIT \\
& Sunitinib & VEGFR-1, VEGFR-2, VEGFR-3, PDGFR- $\alpha$ and - $\beta$, KIT, RET, FLT3, CSF-1R \\
& Vandetanib & VEGFR-2, EGFR, RET \\
mTOR & Axitinib & VEGFR-1, VEGFR-2, VEGFR-3 \\
Farnesyltransferase & Pazopanib & VEGFR-1, VEGFR-2, VEGFR-3, PDGFR- $\alpha$ and - $\beta$, KIT \\
& Temsirolimus & None \\
& Everolimus & None \\
Src & Tipifarnib & For all FTIs: lamin A, PxF, RhoB, cyclic guanosine \\
& Lonafarnib & Monophosphate phosphodiesterase $\alpha$, rhodopsin kinase, transducin \\
& AZD3409 & Geranylgeranyl transferase \\
MEK1/2 & Dasatinib & Abl \\
PKC $\beta$ & AZD0530 & Abl \\
\hline
\end{tabular}

CSF-1R, colony-stimulating factor 1 receptor; FLT3, FMS-like tyrosine kinase 3; PDGFR, platelet-derived growth factor receptor; $\mathrm{PxF}$, human perioxisomal farnesylated protein.

adjuvant setting, alternative trastuzumab-based combinations were developed, such as combinations with vinorelbine (Burstein et al. 2001, 2003, Papaldo et al. 2006, De Maio et al. 2007) and capecitabine (Bartsch et al. 2007, Schaller et al. 2007). Combinations of trastuzumab with polychemotherapy have been also studied. Regimens including a taxane and a platinum salt (Burris et al. 2004, Pegram et al. 2004, Robert et al. 2006) showed high response rates, but induced severe nonhematologic toxicities, including fatigue, nausea, vomiting, and neurotoxicity, which limit their use in clinical practice of metastatic breast cancer where palliation is the goal of treatment. An active triplet for patients previously treated with taxanes is the combination of trastuzumab with gemcitabine and vinorelbine that produced a response rate of $50 \%$ as second line therapy (Morabito et al. 2006b). However, there is yet no prospective demonstration of convenience of three-drug versus two-drug trastuzumabbased combinations in metastatic breast cancer.

An open question is the opportunity of continuing trastuzumab in combination with a non cross-resistant chemotherapeutic regimen in patients who progress on trastuzumab. Preclinical observations support the use of trastuzumab treatment beyond progression (Fujimoto-Ouchi et al. 2005). Until recently, clinical evidences in contrast or in favor of this hypothesis came only from retrospective (Fountzilas et al. 2003,
Gelmon et al. 2004, Tripathy et al. 2004, Bartsch et al. 2006, Montemurro et al. 2006) or phase II studies (Bartsch et al. 2007, 2008). At ASCO 2008, two phase III trials have been reported. In the one not yet published in extenso (O'Shaughnessy et al. 2008), trastuzumab was added to lapatinib and compared with lapatinib alone, as salvage treatment in 296 patients; a very small advantage was shown in TTP (median 2.8 vs 1.9 months), that was statistically significant $(P=0.029)$ but does not represent a clinically significant progress, with no advantage in response rate and survival. The other phase III study (von Minckwitz et al. 2009) assessed the efficacy of continuing trastuzumab combined with capecitabine compared with capecitabine alone in patients progressing $<6$ weeks since the end of the last trastuzumab cycle. The study was planned to detect a prolongation of 1 month in TTP, and required 482 patients, with the first interim analysis planned after 150 events. However, it was performed after 82 events and, although the Independant Data Monitoring Committee suggested to continue the study, it was stopped with 156 randomized patients because of slowing accrual. TTP was slightly prolonged in the combination arm (median 8.2 vs 5.6 months, $P=0.034$ ) and response rate was increased (48 vs $27 \%$, $P=0.0068$ ) but no significant difference was found in survival. Overall, the level of evidence actually available in favor of continuing trastuzumab beyond 
Table 2 Randomized trials of target-based agents plus chemotherapy in metastatic breast cancer

\begin{tabular}{|c|c|c|c|c|c|c|c|c|c|c|}
\hline Agent & Author (year) & $\begin{array}{l}\text { Study } \\
\text { phase }\end{array}$ & Line & $\begin{array}{l}\text { No. of } \\
\text { patients }\end{array}$ & Arms & $\mathbf{R R}(\%)$ & $\begin{array}{l}\text { TTP } \\
\text { (months) }\end{array}$ & $\boldsymbol{P}$ & $\begin{array}{l}\text { OS } \\
\text { (months) }\end{array}$ & $\boldsymbol{P}$ \\
\hline \multirow[t]{9}{*}{ Trastuzumab } & $\begin{array}{l}\text { Slamon et al. } \\
\text { (2001) }\end{array}$ & Phase III & 1 & 469 & $\begin{array}{l}\text { Chemotherapy + trastuzumab } \\
\text { versus chemotherapy }\end{array}$ & $\begin{array}{l}50 \\
32\end{array}$ & $\begin{array}{l}7.4 \\
4.6\end{array}$ & \multirow[t]{5}{*}{$<0.001$} & $\begin{array}{l}25.1 \\
20.3\end{array}$ & \multirow[t]{5}{*}{0.046} \\
\hline & \multirow{2}{*}{$\begin{array}{l}\text { Gasparini et al. } \\
(2007)\end{array}$} & \multirow[t]{2}{*}{ Phase II } & \multirow[t]{2}{*}{1} & \multirow[t]{2}{*}{123} & Paclitaxel + trastuzumab & 75 & $9.9^{\mathrm{a}}$ & & NR & \\
\hline & & & & & versus paclitaxel & 56.9 & $6.6^{\mathrm{a}}$ & & NR & \\
\hline & \multirow{2}{*}{$\begin{array}{l}\text { Marty et al. } \\
\text { (2005) }\end{array}$} & \multirow[t]{2}{*}{ Phase II } & \multirow[t]{2}{*}{1} & \multirow[t]{2}{*}{186} & Docetaxel+trastuzumab & 61 & 11.7 & & 31.2 & \\
\hline & & & & & versus docetaxel & 34 & 6.1 & & 22.7 & \\
\hline & \multirow{2}{*}{$\begin{array}{l}\text { Robert et al. } \\
\text { (2006) }\end{array}$} & \multirow[t]{2}{*}{ Phase III } & \multirow[t]{2}{*}{1} & \multirow[t]{2}{*}{196} & Paclitaxel + carboplatin + trastuzumab & 52 & $10.7^{\mathrm{a}}$ & \multirow[t]{2}{*}{0.03} & 35.7 & \multirow[t]{2}{*}{0.76} \\
\hline & & & & & versus paclitaxel + trastuzumab & 36 & $7.1^{\mathrm{a}}$ & & 32.2 & \\
\hline & \multirow{2}{*}{$\begin{array}{r}\text { Von Minckwitz } \\
\text { et al. (2009) }\end{array}$} & \multirow[t]{2}{*}{ Phase III } & \multirow[t]{2}{*}{$1-2^{b}$} & \multirow[t]{2}{*}{156} & Capecitabine + trastuzumab & 48.1 & 8.2 & \multirow[t]{2}{*}{0.03} & 25.5 & \multirow[t]{2}{*}{0.26} \\
\hline & & & & & versus capecitabine & 27 & 5.6 & & 20.4 & \\
\hline Cetuximab & Carey et al. & Phase II & $1-2-3$ & 102 & Cetuximab & 6 & NR & & NR & \\
\hline & (2008) & & & & versus cetuximab + carboplatin & 17 & $2^{\mathrm{a}}$ & & NR & \\
\hline & O'Shaughnessy & Phase II & $1-2$ & 154 & Irinotecan + carboplatin & 28 & $4.5^{\mathrm{a}}$ & & 12.3 & \\
\hline & et al. (2007) & & & & versus irinotecan + carboplatin + cetuximab & 33 & $4.7^{\mathrm{a}}$ & & 12.6 & \\
\hline Lapatinib & Geyer et al. & Phase III & $2-3$ & 324 & Capecitabine + lapatinib & 22 & 8.4 & $<0.001$ & NR & \\
\hline & $(2006)$ & & & & versus capecitabine & 14 & 4.4 & & NR & \\
\hline & O'Shaughnessy & Phase III & $3-4$ & 296 & Trastuzumab + lapatinib & 10.3 & $3^{a}$ & 0.008 & 12.9 & 0.106 \\
\hline & et al. (2008) & & & & versus lapatinib & 6.9 & $2.1^{\mathrm{a}}$ & & 9.75 & \\
\hline & Di Leo et al. & Phase III & 1 & 580 & Paclitaxel + lapatinib & 35.1 & 6.7 & 1.142 & 22.8 & 0.216 \\
\hline & (2007) & & & & versus paclitaxel+placebo & 25.3 & 5.3 & & 20 & \\
\hline Bevacizumab & Miller et al. & Phase III & $1-2-3$ & 462 & Capecitabine + bevacizumab & 19.8 & $4.86^{\mathrm{a}}$ & 0.857 & 15.1 & Not reported \\
\hline & $(2005 a, b)$ & & & & versus capecitabine & 9.1 & $4.17^{\mathrm{a}}$ & & 14.5 & \\
\hline & Miller et al. & Phase III & 1 & 722 & Paclitaxel+bevacizumab & 36.9 & $11.8^{\mathrm{a}}$ & $<0.001$ & 26.7 & 0.16 \\
\hline & (2007) & & & & versus paclitaxel & 21.2 & $5.9^{\mathrm{a}}$ & & 25.2 & \\
\hline & Miles et al. & Phase III & 1 & 736 & Docetaxel+bevacizumab $(7.5 \mathrm{mg} / \mathrm{kg})$ & 55.2 & 8.7 & 0.0318 & NR & \\
\hline & (2008) & & & & versus docetaxel+bevacizumab & 63.1 & 8.8 & 0.0099 & NR & \\
\hline & & & & & $(15 \mathrm{mg} / \mathrm{kg})$ versus docetaxel + placebo & 44.4 & 8.0 & & NR & \\
\hline Vandetanib & Boer et al. & Phase II & 2 & 64 & Docetaxel+vandetanib & Not reported & 8.75 & & NR & \\
\hline & $(2007)$ & & & & versus docetaxel+placebo & & 6 & & NR & \\
\hline Axitinib & Rugo et al. & Phase II & 1 & 168 & Docetaxel + axitinib & 40.2 & 8.2 & & NR & \\
\hline & (2007) & & & & versus docetaxel+placebo & 23.2 & 7.0 & & NR & \\
\hline Pazopanib & Slamon et al. & Phase II & 1 & 141 & Lapatinib + pazopanib & 36.2 & NR & & NR & \\
\hline & (2008) & & & & versus lapatinib & 22.2 & NR & & NR & \\
\hline
\end{tabular}

RR, response rate; TTP, time to progression; OS, overall survival; NR, not reached.

aProgression-free survival.

${ }^{\mathrm{b}}$ Pretreated with trastuzumab. 
progression remains weak, because of limitations of studies performed, and it suggests that the advantage deriving from continuing trastuzumab might be very small, if any.

The evidence of a molecular cross-talk between ER and the ErbB-2 pathway, and the observation that ErbB-2 overexpression is associated with preclinical and clinical resistance to hormonal therapy, suggested that combining treatments targeting both pathways may provide additional benefits for breast cancer patients (Nicholson et al. 2004, Normanno et al. $2005 c, d$ ). A phase III trial (TANDEM) investigated the efficacy of adding trastuzumab to anastrozole alone as first-line therapy in postmenopausal patients with ER and ErbB-2 positive metastatic breast cancer (Mackey et al. 2006). The results of this trial led to the extension of trastuzumab indication thanks to a significant improvement in progression free survival (4.8 vs 2.4 months) and response rate (20.3 vs $6.8 \%$; Table 3 ). However, the very poor outcome even in the winner arm prevents to consider this combination as a reasonable standard of treatment. In addition, the hypothesis that endocrine treatment is not effective at all and that better trastuzumab-based combinations might be used in this subgroup of patients is not ruled out by the TANDEM study. Two phase III trials are evaluating the effect of adding trastuzumab to letrozole or tamoxifen in ER/ErbB-2 positive patients.

Some large international randomized phase III clinical studies demonstrated the efficacy of adjuvant trastuzumab in women with ErbB-2 positive early breast cancer (Table 4); unfortunately, some of them have not been published in extenso, although being presented in 2005 for the first time (N9831) or repeatedly in subsequent years (BCIRG 006; Slamon et al. 2006). Despite differences in the patient population and design, all these studies showed similar results, namely a significant improvement of diseasefree survival, with a hazard ratio (HR) of $0.46-0.67$ for women receiving trastuzumab, with the exception of PACS 04 trial, an underpowered study where a 0.86 HR was found (Spielmann et al. 2007). Some trials also demonstrated a prolongation of overall survival. The standard duration of adjuvant trastuzumab treatment is now 1 year, based on HERA and Joint Analysis (NSABP B-31 and NCCTG N9831) results (Piccart-Gebhart et al. 2005, Romond et al. 2005, Smith et al. 2007a). However, it might be not the optimal one. The HERA trial will compare 2 years with 1 year of trastuzumab. On the other hand, the FinHer trial showed that 9 weeks of trastuzumab given concurrently with three cycles of docetaxel or vinorelbine and followed by three cycles of fluorouracil, epirubicin and cyclophosphamide are enough to significantly improve disease-free survival (Joensuu et al. 2006). Two further randomized phase III trials are testing the efficacy of a shorter duration of adjuvant trastuzumab: the Short-HER Trial (NCT00629278), an Italian trial of two different adjuvant chemotherapy regimens plus 3 vs 12 months of trastuzumab, and the PHARE study (NCT00381901) that is currently comparing 6 with 12 months of adjuvant trastuzumab.

Another unanswered question is whether giving trastuzumab as sequential or partially combined with chemotherapy does produce different efficacy. The only direct comparison currently available, in the NCCTG N9831 trial (Perez 2005), suggests that giving trastuzumab concomitantly with paclitaxel for 3 months and then as single agent up to 1 year is more effective than giving it sequentially after chemotherapy. Finally, the unpublished BCIRG 006 suggests the possibility that a non-anthracycline containing regimen (docetaxel and carboplatin plus trastuzumab) might be effective approximately as a sequential scheme with AC followed by docetaxel plus trastuzumab. This might represent a useful therapeutic opportunity in patients not candidate to anthracyclines. Efficacy of adjuvant trastuzumab is still unknown among patients with very small tumors $(<1 \mathrm{~cm})$ and among those who do not receive adjuvant chemotherapy.

\section{Lapatinib}

Lapatinib is an oral, dual TKI of both EGFR and ErbB-2. In preclinical studies, lapatinib produced growth inhibition in a variety of human tumor cell lines overexpressing either EGFR or ErbB-2, including breast cancer (Rusnak et al. 2001). Thanks to its ability of binding also with the truncated form of ErbB-2 (p95 ErbB-2) that lacks the extracellular domain, lapatinib might be effective in ErbB-2 positive tumors that are resistant to trastuzumab (Scaltriti et al. 2007). Following early clinical trials (Blackwell et al. 2005, Burris et al. 2005, Spector et al. 2005, Burstein et al. $2008 b$ ), a phase III registrative trial, in patients with ErbB-2 positive metastatic breast cancer who had received multiple previous treatments, demonstrated that the addition of lapatinib to capecitabine significantly prolonged TTP (Geyer et al. 2006; Table 2), with no difference in overall survival. The latter result might be jeopardized by crossover that was allowed after the anticipated study closure due to the positive results at an interim analysis of TTP. Treatment was well tolerated and the rate of adverse events was similar in the two arms, the main difference being an 
Table 3 Randomized trials of target-based agents in combination with endocrine therapy in metastatic breast cancer

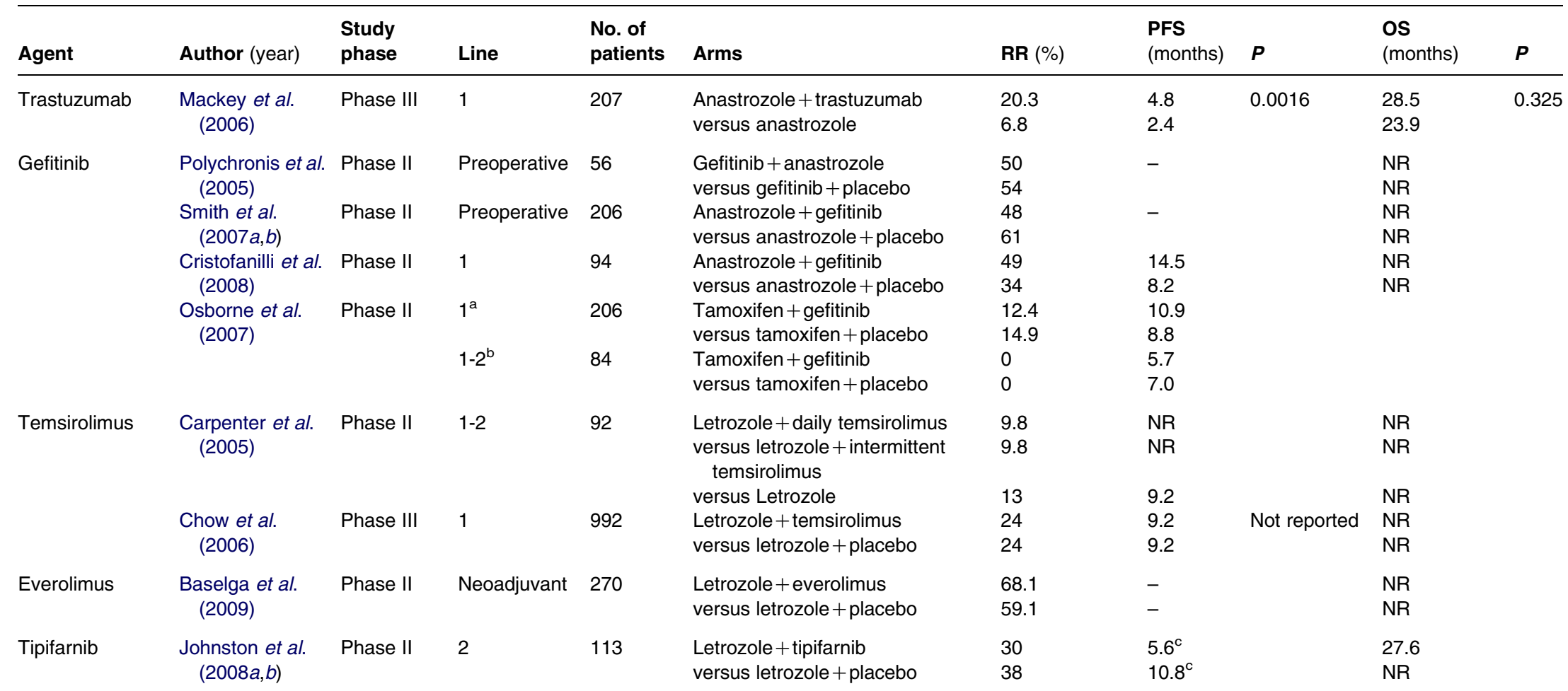

RR, response rate; PFS, progression-free survival; OS, overall survival; NR, not reached.

${ }^{a}$ Not pretreated with aromatase inhibitors.

Pretreated with aromatase inhibitors.

${ }^{\mathrm{c}}$ Time to progression. 


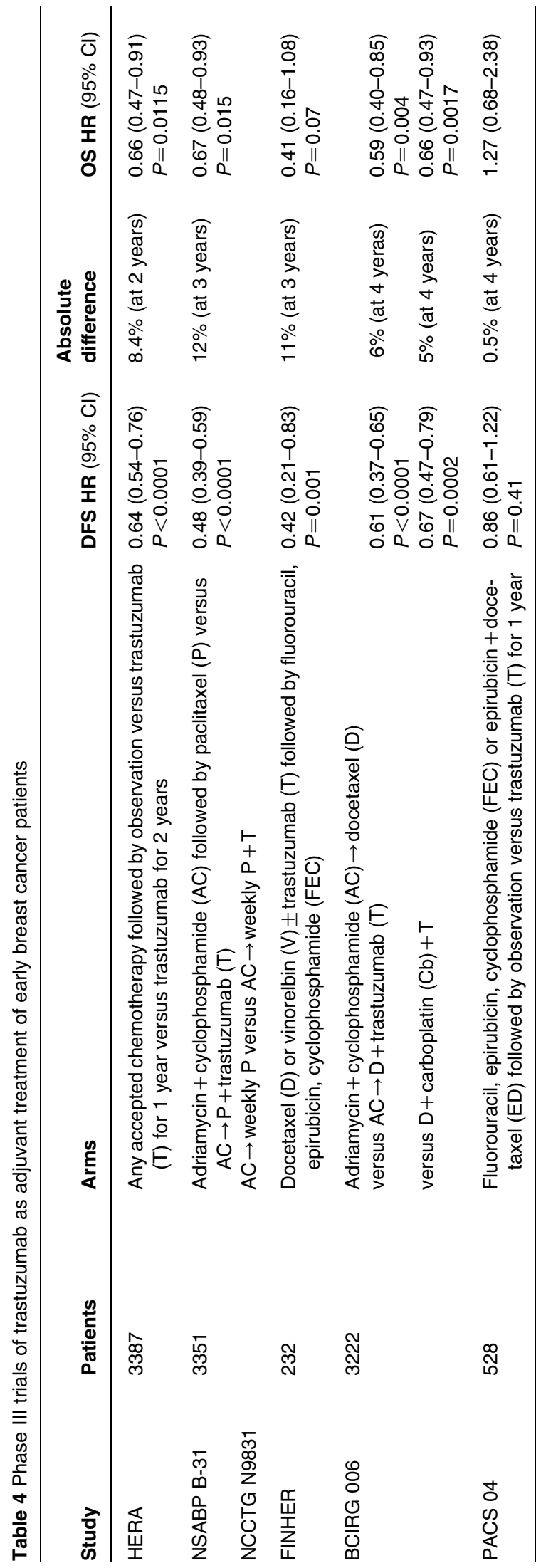

increase of grade 1 and 2 diarrhea in the combination arm (45 vs 28\%). Another phase III trial assessed the worth of adding lapatinib to chemotherapy, namely paclitaxel, in a population of 580 patients with ErbB-2 negative/untested advanced breast cancer (Di Leo et al. 2007). The result was negative, with no difference in TTP, the primary endpoint, except for a small subgroup of 86 patients whose tumor resulted to be ErbB-2 positive at pathology revision, where the addition of lapatinib prolonged TTP. Similar results have been recently reported in the phase III EGF30008 study testing the efficacy of lapatinib added to endocrine treatment with letrozole (Johnston et al. 2008a). The rationale of this study was based on preclinical studies showing that the combination of lapatinib with antiestrogens might delay or prevent the development of resistance to lapatinib in ErbB-2-overexpressing/ERpositive breast cancer cells and might overcome endocrine resistance (Chu et al. 2005, Xia et al. 2006). Lapatinib plus letrozole significantly prolonged PFS as compared with letrozole alone among postmenopausal patients with ER-positive tumors. The benefit, however, seems to be limited to patients with ErbB-2 positive metastatic breast cancer, and is not evident among those with ErbB-2 negative tumors. All the above evidences, considered together, strongly support the hypothesis that lapatinib therapeutic effect is prevalently limited to patients with ErbB-2 positive breast cancer.

Promising preliminary results have been reported with lapatinib as single agent. A phase II study of lapatinib monotherapy in relapsed or refractory inflammatory breast cancer showed, in ErbB-2 positive patients, a response rate of $62 \%$, with additional $21 \%$ of the patients experiencing stabilization of disease. In contrast, only $8.3 \%$ of EGFR positive/ErbB-2 negative patients achieved a partial response (Spector et al. 2006). Biomarker analyses of tumor biopsies showed that co-expression of phospho-ErbB-2 and phosphoErbB-3 was predictive of lapatinib response.

Usefulness of lapatinib in an earlier phase of breast cancer is not definite, yet. Two randomized phase III studies, the ALTTO and NeoALTTO trials, are evaluating its efficacy as single agent or in combination with trastuzumab as compared with trastuzumab as single agent in the adjuvant and neoadjuvant treatment of ErbB-2 positive breast cancer patients.

Because of the unexpected cardiac toxicity evidenced in trastuzumab trials, great attention has been given to cardiac safety of lapatinib. A review of cardiotoxicity data of nearly 3000 patients enrolled in 18 phase I-III clinical trials, including 1674 breast 
cancer patients, treated with lapatinib alone or in combination with other agents, reported an incidence of symptomatic or asymptomatic decline in left ventricular ejection fraction of $1.3 \%$ (Perez et al. 2006). Lapatinib does not appear to increase the risk of cardiomyopathy, even when combined with trastuzumab (Storniolo et al. 2007).

\section{Pertuzumab}

Pertuzumab is a humanized recombinant $\mathrm{mAb}$ directed against the extracellular dimerization domain of the ErbB-2 receptor. This antibody directly inhibits the dimerization of the ErbB-2 protein with other ErbB family receptors, preventing the activation of downstream signaling pathways. The different and potentially complementary mechanism of action is the rationale for associating pertuzumab with trastuzumab (Nahta et al. 2004). These two mAbs have been combined in a phase II study, in 66 heavily pretreated patients affected by locally advanced or metastatic ErbB-2 positive breast cancer, whose disease had progressed during trastuzumab therapy (Gelmon et al. 2008). Frequent toxicities included diarrhea $(63 \%)$, pain $(35 \%)$, nausea/vomiting $(30 \%)$, mucositis $(32 \%)$, and skin rash $(26 \%)$. A response rate of $18.2 \%$ and a long lasting stabilization of disease in $21.2 \%$ of patients were observed. Randomized phase II and phase III trials are evaluating the effectiveness of pertuzumab in combination with trastuzumab and chemotherapy as first-line therapy in metastatic disease.

\section{Anti-angiogenic agents in breast cancer}

Anti-angiogenic agents in advanced phase of clinical development in breast cancer include neutralizing antibodies against VEGF (bevacizumab) and TKIs of VEGFRs (sorafenib, sunitinib, vandetanib, axitinib, pazopanib; Table 1).

\section{Bevacizumab}

Bevacizumab is a humanized $\mathrm{mAb}$ that binds VEGF and prevents its interaction with VEGF receptors, thus leading to inhibition of VEGF-induced angiogenesis. Bevacizumab can be administered safely, without dose-limiting toxicities, up to the dose of $10 \mathrm{mg} / \mathrm{kg}$ every 2 weeks, and can be combined with chemotherapy without apparent synergistic toxicity (Gordon et al. 2001, Margolin et al. 2001). In pretreated metastatic breast cancer bevacizumab has very limited activity as single agent (Cobleigh et al.
2003) and, when added to capecitabine, produced an increase in response rates that did not translate into improved PFS or overall survival in a randomized phase III trial (Miller et al. 2005a).

On the contrary, the addition of bevacizumab to first-line chemotherapy has been found effective in two phase III trials (Table 2). In the E2100 trial, bevacizumab plus paclitaxel significantly prolonged progression-free survival (median 11.8 vs 5.9 months; HR of progression $0.60, P<0.001$ ), and increased the objective response rate ( 36.9 vs $21.2 \%$ ) of 722 patients with metastatic breast cancer as compared with paclitaxel alone, although there was no advantage in survival (Miller et al. 2007). In the AVADO trial, 736 patients with ErbB-2 negative metastatic breast cancer were randomized to receive docetaxel plus bevacizumab (either the dose of 7.5 or $15 \mathrm{mg} / \mathrm{kg}$ ) or docetaxel alone (Miles et al. 2008). At both doses, bevacizumab in combination with docetaxel significantly improved progression-free survival (HR 0.69 and 0.61 respectively) and response rate (55.2\% and 63.1 vs $44.4 \%$ respectively), as compared with docetaxel alone. Combination treatment was well tolerated at both doses of bevacizumab.

Preclinical studies have shown that initial events in the development of metastasis are VEGF-dependent, suggesting that angiogenesis inhibitors might be more effective in the adjuvant setting. The ECOG E5103 trial will evaluate the efficacy of the addition of bevacizumab to four cycles of $\mathrm{AC}$ followed by 12 courses of weekly paclitaxel and the role of bevacizumab as maintenance therapy. In the BEATRICE trial, standard adjuvant chemotherapy will be compared with chemotherapy plus bevacizumab for 1 year in early triple negative breast cancer. Finally, the BETH study will evaluate the efficacy of the combination of adjuvant bevacizumab, trastuzumab and chemotherapy versus chemotherapy plus trastuzumab in ErbB-2 positive breast cancer patients.

In the neoadjuvant setting, preliminary safety results are available for the combination of bevacizumab and docetaxel, showing a good tolerability of such treatment (Lyons et al. 2006). Bevacizumab was also tested in combination with doxorubicin and docetaxel as neoadjuvant treatment of women with inflammatory breast cancer (Wedam et al. 2006). Fourteen of 21 enrolled patients experienced a clinical partial response and showed a decrease in vascular permeability on dynamic contrast-enhanced magnetic resonance imaging that was consistent with reduced angiogenesis. Moreover, this study indicated a potential direct anti-tumor effect of bevacizumab, as 
suggested by increased apoptosis and decreased phosphorylated VEGFR2 in tumor cells. However, the role of VEGFR2 in the survival of breast cancer cells has not been formally proven yet. A pilot trial of neoadjuvant letrozole in combination with bevacizumab in postmenopausal women with newly diagnosed operable breast cancer showed an overall response rate of 74\% (Forero-Torres et al. 2008).

\section{Sorafenib}

Sorafenib is an oral multikinase inhibitor with activity on cancer cell proliferation and angiogenesis (Wilhelm et al. 2004). Sorafenib inhibits Raf kinase isoforms (Raf-1, wild-type B-Raf, and mutant B-Raf) and Rafdependent activation of MAPK pathway in breast cancer cells that carry mutations of both K-Ras and B-Raf (Wilhelm et al. 2004). Sorafenib also inhibits several receptor tyrosine kinases involved in angiogenesis such as VEGFR-2, VEGFR-3, platelet-derived growth factor receptor (PDGFR)- $\beta$, and stem-cell factor receptor (c-KIT). The inhibition of receptor tyrosine kinases autophosphorylation occurs at significantly lower drug concentration as compared with the blockade of the Raf/MEK/MAPK pathway, which might require inhibition of multiple Raf isoforms (Wilhelm et al. 2004). Once-daily oral dosing of sorafenib demonstrated broad-spectrum anti-tumor activity in colon, breast, and non-small-cell lung cancer xenografts (Wilhelm et al. 2004). Inhibition of the Raf/MEK/MAPK pathway was demonstrated in some but not all models, whereas a significant reduction of neovascularization was found in all the xenograft models, suggesting that both mechanisms contribute to the growth inhibitory activity of sorafenib (Wilhelm et al. 2004).

Negative results were reported with sorafenib as single agent in patients with metastatic breast cancer (Moreno-Aspitia et al. 2006). In this study, higher circulating ErbB-2 levels and/or higher baseline serum VEGF levels were associated with shorter TTP. Studies of sorafenib in combination with chemotherapeutic agents in metastatic breast cancer patients are ongoing.

\section{Sunitinib}

Sunitinib is an oral multitarget receptor TKI of VEGFR-1, VEGFR-2 and VEGFR-3, PDGFRs- $\alpha$ and $-\beta$, c-KIT, glial cell line-derived neurotrophic factor receptor (rearranged during transfection; RET), FMS-like tyrosine kinase 3, and colony-stimulating factor 1 receptor (Chow \& Eckhardt 2007).
In breast cancer tumor xenograft models, sunitinib demonstrated a significant anti-tumor activity (Abrams et al. 2003). Moreover, activity of sunitinib has been demonstrated in an in vivo model of breast cancer bone metastases and tumor-associated osteolysis (Murray et al. 2003). Interestingly, a recent report showed that short-term treatment with sunitinib or with other VEGFR-TKIs (sorafenib and SU10944) produced an increase in tumor growth and metastatization in different orthotopic mice models including breast cancer, suggesting that the schedule and the duration of treatment might significantly affect the efficacy of these drugs (Ebos et al. 2009).

A phase II study of sunitinib $(50 \mathrm{mg} / \mathrm{day}, 4$ weeks on/2 weeks off) in patients with anthracycline and taxane-resistant metastatic breast cancer showed a response rate of $11 \%$ (Burstein et al. 2008a). Interestingly, among the 'triple negative' patients, the response rate was $15 \%$, while in the ErbB-2 positive, trastuzumab pretreated patients, the response rate was $25 \%$. The most frequently reported adverse effect was fatigue, followed by nausea, diarrhea, mucosal inflammation, and anorexia. However, a randomized phase III trial evaluating single-agent sunitinib versus singleagent capecitabine for the treatment of patients with advanced breast cancer after failure of standard treatment was recently discontinued for futility. Phase II and phase III clinical trials of sunitinib in combination with chemotherapeutic agents (capecitabine, docetaxel, paclitaxel) or target-based agents (bevacizumab or trastuzumab) are ongoing.

\section{Vandetanib}

Vandetanib is a small molecule receptor TKI that inhibits VEGFR-2, EGFR, and RET and that has shown anti-tumor activity in a broad range of preclinical models (Wedge et al. 2002, Ciardiello et al. 2003, 2004). Phase I studies of vandetanib in patients with advanced solid tumors have demonstrated that the once-daily oral administration at $100-300 \mathrm{mg} /$ day is well tolerated (Tamura et al. 2006). However, the drug showed limited activity in patients with metastatic breast cancer, who had received prior treatment with an anthracycline and taxanes, as no objective response was observed and only one patient experienced stable disease $\geq 24$ weeks (Miller et al. $2005 \mathrm{~b}$ ). A randomized phase II study of the combination of vandetanib (100 mg daily) plus docetaxel $\left(100 \mathrm{mg} / \mathrm{m}^{2} 3\right.$ weeks) versus docetaxel plus placebo as second-line treatment for advanced breast cancer failed to demonstrate any advantage for the combination (Table 2; Boer et al. 2007). An Italian randomized 
phase II trial (the ZACFAST study) will compare two doses of vandetanib (100 and $300 \mathrm{mg}$ ) versus placebo in combination with fulvestrant, an ER antagonist with no estrogen agonist effects, in postmenopausal patients with endocrine responsive metastatic breast cancer (Morabito et al. 2009).

\section{Axitinib}

Axitinib is an oral potent inhibitor of VEGFRs 1, 2, and 3 (reviewed in Morabito et al. 2006a). Preclinical studies demonstrated that axitinib blocks angiogenesis and tumor blood flow in tumor models (Inai et al. 2004). A phase I trial identified axitinib $5 \mathrm{mg}$ twice daily as the recommended clinical dose; hypertension, hemoptysis, and stomatitis were dose-limiting toxicities (Rugo et al. 2005). A randomized, double-blind phase II study evaluated the activity of the combination of axitinib ( $5 \mathrm{mg}$ twice daily) and docetaxel $\left(80 \mathrm{mg} / \mathrm{m}^{2}\right)$ compared with docetaxel plus placebo as first-line treatment of 168 patients with metastatic breast cancer (Table 2; Rugo et al. 2007). The combination had an acceptable safety profile, but showed only a modest improvement in TTP (8.2 vs 7.0 months, $P=0.052$ ). In a predefined subgroup analysis, TTP was increased by the addition of axitinib to docetaxel only in patients that were previously treated with adjuvant chemotherapy ( $9.0 \mathrm{vs}$ 6.3 months, $P=0.012$ ).

\section{Pazopanib}

Pazopanib is an oral small molecule multitargeted receptor TKI of VEGFR-1, -2, -3, PDGFR- $\alpha$, PDGFR- $\beta$, and c-kit tyrosine kinases (Kumar et al. 2007). Maximum tolerated dose (MTD) was not achieved in a phase I study, but the recommended phase II dose was defined at $800 \mathrm{mg} /$ day (Hurwitz et al. 2005). The most common adverse events were nausea, hypertension, diarrhea, fatigue, anorexia, vomiting, and hair depigmentation. A randomized phase II study evaluated the combination of pazopanib and lapatinib versus lapatinib alone as first-line therapy of 141 patients with ErbB-2 positive metastatic breast cancer (Table 2; Slamon et al. 2008). The combination of pazopanib and lapatinib showed an increased response rate when compared with lapatinib monotherapy (36.2 vs $22.2 \%$ ), but no difference in progression rate at week 12 , the primary endpoint of the study. Ongoing studies are evaluating the activity of pazopanib in combination with lapatinib in inflammatory breast cancer, with exemestane in postmenopausal ER+ breast cancer or as single agent in patients with metastatic breast cancer pretreated with chemotherapy.

\section{Inhibitors of signaling pathways}

A number of agents directed against different signaling pathways have been developed. As we will discuss, the majority of these agents have been explored in unselected breast cancer patients and have shown little or no activity. However, preclinical and clinical findings suggest a potential role of some of these agents in specific settings.

\section{Anti-EGFR agents}

\section{Gefitinib}

Gefitinib is an oral EGFR TKI. In preclinical studies, this drug inhibited the growth of a wide range of EGFR-expressing human cancer cell lines, including breast cancer cells (Moasser et al. 2001, Moulder et al. 2001, Normanno et al. 2002, Campiglio et al. 2004).

Several phase II clinical trials with gefitinib as single agent in breast cancer patients have been reported (Normanno et al. 2005c,d). These studies showed no significant clinical activity in pretreated advanced breast cancer patients (Albain et al. 2002, Robertson et al. 2003, Baselga et al. 2005, von Minckwitz et al. 2005). Similarly, addition of gefitinib to chemotherapy did not result in an improvement of anti-tumor activity (Fountzilas et al. 2005, Ciardiello et al. 2006).

Pharmacodynamic studies in breast cancer patients treated with gefitinib showed that EGFR phosphorylation was successfully inhibited in tumor biopsies in all patients, suggesting that resistance to gefitinib is due to lack of tumor dependence upon EGFR (Baselga et al. 2005). In agreement with this hypothesis, preclinical studies showed that EGFR-independent activation of either MAPK or AKT signaling might mediate resistance to gefitinib (Moasser et al. 2001, Moulder et al. 2001, Normanno et al. 2006). Activation of the insulin-like growth factor type 1 receptor (IGF-1R), a tyrosine kinase receptor that is a powerful activator of PI3K/AKT signaling, has also been associated with both de novo and acquired resistance to gefitinib (Jones et al. 2004, Camirand et al. 2005). More recently, it has been shown that breast cancer cells that co-express EGFR, ErbB-2, and ErbB-3, such as SK-Br-3 cells, escape the activity of EGFR-TKIs through ErbB-2dependent activation of the ErbB-3/PI3K/AKT pathway (Sergina et al. 2007). However, this mechanism of resistance developed following short treatment with EGFR-TKIs (up to $96 \mathrm{~h}$ ). When SK-Br3 breast cancer cells were exposed for a long term (5-8 months) to the drug, a persistent EGFR-independent activation of MAPK and increased sensitivity to MEK inhibitors were observed (Normanno et al. 2008). 
Preclinical studies also support the use of EGFRTKIs in combination with anti-hormonal agents. Increased levels of expression of EGFR and/or ErbB-2 and increased sensitivity to anti-EGFR agents have been found in breast cancer cells with acquired resistance to tamoxifen, letrozole, or fulvestrant, as well as in estrogen-dependent cells cultured for long term in absence of estrogen, an in vitro condition that resembles anti-estrogen therapy in vivo (Knowlden et al. 2003, Martin et al. 2003). In addition, it has been shown that treatment of breast cancer cells with combinations of anti-EGFR and/or anti-ErbB-2 drugs and endocrine agents prevents the occurrence of resistant clones (Gee et al. 2003, Xia et al. 2006). However, mixed results have been obtained in clinical trials.

Two studies of preoperative gefitinib in combination with anastrozole showed contrasting results (Table 3 ). In a randomized phase II clinical trial, 56 patients with ER $+/$ EGFR + primary untreated breast cancer were treated with gefitinib and anastrozole or gefitinib plus placebo (Polychronis et al. 2005). Ultrasonography revealed a significant decrease of tumor mass in $50 \%$ of patients treated with gefitinib and anastrozole, and in $54 \%$ of patients that received gefitinib as single agent. Negative results were found in a neoadjuvant randomized phase II clinical trial (Smith et al. 2007b), in which 206 patients were randomized to receive anastrozole plus gefitinib or anastrozole plus placebo for 2 weeks followed by gefitinib for 14 weeks or anastrozole plus placebo for 16 weeks. Neither biological nor clinical activity of anastrozole was enhanced by the addition of gefitinib. However, it must be emphasized that this trial did not require EGFR positivity as inclusion criteria.

No clinical benefit was found with gefitinib plus anastrozole in patients with ER + advanced breast cancer, who had previously failed hormonal therapy (Mita et al. 2005), while a significant increase in median progression free survival (14.5 vs 8.2 months) was seen with the same combination as first-line treatment of metastatic breast cancer (Cristofanilli et al. 2008). Finally, the results of a randomized phase II trial of gefitinib or placebo in combination with tamoxifen in patients with ER + and/or PR+ metastatic breast cancer showed a modest advantage in progression free survival with the combination in women with newly diagnosed cancer or who had completed adjuvant tamoxifen from at least 1 year, but not in patients previously treated with aromatase inhibitors (Table 3; Osborne et al. 2007).

Overall, these data suggest that gefitinib might enhance the activity of anti-estrogen therapies by preventing the resistance to endocrine therapy. However, this phenomenon is likely to occur in specific subsets of patients that develop an EGFRdependent mechanism of resistance. Indeed, different molecular mechanisms seem to be involved in the resistance to endocrine therapy, as we will discuss in the next paragraphs.

Finally, gefitinib has been described to have activity on bone pain in selected breast cancer patients (Albain et al. 2002, von Minckwitz et al. 2005). The mechanism involved in this phenomenon has not been clarified yet. However, we have shown that gefitinib affects the ability of bone marrow stromal cells to secrete pro-osteoclastogenic factors and to induce osteoclast differentiation, thus suggesting a specific activity of this agent on the pathogenesis of bone metastases (Normanno et al. 2005b).

\section{Erlotinib}

Erlotinib is an oral reversible inhibitor of the EGFR tyrosine kinase, which has shown a potent anti-tumor activity in preclinical studies (Normanno et al. 2003). Erlotinib is also able to block the ErbB-2 kinase in intact cells through direct interaction with ErbB-2 (Schaefer et al. 2007). However, this drug is 12-fold less active against ErbB-2 kinase as compared with the EGFR kinase. A pharmacodynamic study showed that treatment of patients with operable breast cancer (stage I-IIIA) with erlotinib (150 mg/day) for 6-10 days before surgery produced a significant reduction of the activation of both EGFR and ErbB-2 (Guix et al. 2008). Erlotinib also induced a statistically significant reduction of AKT and MAPK phosphorylation and suppressed ER phosphorylation at ser118 in ER+ breast tumors. A complete cell cycle response, as defined by a $<1 \%$ Ki67 index after neoadjuvant therapy, was observed in 17 patients, 16 of which were $\mathrm{ER}+$. Little activity in metastatic breast cancer patients has been shown with erlotinib as single agent (Dickler et al. 2009) and in combination with letrozole (Mayer et al. 2006).

\section{Cetuximab}

Cetuximab is a chimeric human-mouse mAb that binds competitively to the extracellular domain of the EGFR, inhibiting its autophosphorylation and inducing its internalization and degradation. In preclinical studies, cetuximab showed anti-tumoral activity against a variety of human tumor xenografts and displayed synergistic effects when used with classical cytotoxic agents and radiation (Normanno et al. 2003, Ciardiello \& Tortora 2008). 
A dose-escalation phase I trial of cetuximab and paclitaxel, as first or second line of treatment, in patients with EGFR-positive advanced breast cancer evidenced a prohibitive dermatologic toxicity and low activity (Modi et al. 2006). A single arm trial evaluating cetuximab in combination with irinotecan in anthracyclines and taxane-pretreated patients with metastatic breast cancer was closed prematurely due to low activity, although a clinical benefit rate of $27 \%$ was reported in patients with triple negative tumors. (Hobday et al. 2008). In a randomized phase II trial in this latter subset, the combination of cetuximab and carboplatin resulted in a response rate of $18 \%$, but most of the patients progressed rapidly (Carey et al. 2008; Table 2). Negative results were also reported with the combination of cetuximab with irinotecan and carboplatin as first- or second-line therapy of metastatic breast cancer patients, although it resulted in activity in the subgroup of the triple negative breast cancer patients (O'Shaughnessy et al. 2007).

\section{mTOR inhibitors}

The mTOR pathway plays a central role in the regulation of cell growth, proliferation, and survival. Although neither mTOR mutations nor its overexpression have been reported in human tumors, signaling pathways that modulate mTOR are frequently deregulated in human cancers, including breast cancer. Rapamycin, the prototype of mTOR inhibitors, inhibited tumor growth in a wide range of experimental malignancies (Bjornsti \& Houghton 2004). Temsirolimus and everolimus are the rapamycin analogues currently in clinical development (Table 1).

\section{Temsirolimus}

Temsirolimus is a water-soluble ester of rapamycin, which demonstrated anti-tumor activity in a variety of cancer models ( $Y u$ et al. 2001). Breast cancer cell lines sensitive to temsirolimus were estrogen dependent, or lacked expression of PTEN and/or overexpressed ErbB-2, while resistant lines shared none of these properties ( $\mathrm{Yu}$ et al. 2001). AKT resulted highly activated in sensitive but only minimally in resistant cell lines. A synergistic effect of the combination of temsirolimus with endocrine therapy has also been shown (deGraffenried et al. 2004). Finally, preclinical findings revealed that temsirolimus has an antiangiogenetic activity by inhibiting VEGF production in tumor cells and by affecting endothelial cell proliferation and morphogenesis (Del Bufalo et al. 2006). A pharmacodynamic study showed that temsirolimus inhibited pS6K activity in peripheral blood mononuclear cells (PBMCs) and tumor tissue in vivo in a parallel fashion, indicating that the PBMCs could be an appropriate surrogate tissue (Peralba et al. 2003).

A randomized phase II study explored the anti-tumor activity of two doses of temsirolimus (75 and $250 \mathrm{mg} /$ week i.v.), in 109 heavily pretreated patients with locally advanced/metastatic breast cancer (Chan et al. 2005). A response rate of $9 \%$ and a median TTP of 12 weeks were reported in the intent-to-treat population. Efficacy was similar for both dose levels but toxicity was more common with the higher dose. Preliminary data from a randomized phase II trial of letrozole with or without oral temsirolimus as first or second line of treatment of locally advanced or metastatic breast cancer showed that the combination treatment resulted well tolerated at the dose of temsirolimus of $10 \mathrm{mg}$ daily or $30 \mathrm{mg}$ for 5 days every 2 weeks (Carpenter et al. 2005; Table 3). However, a large randomized, placebo-controlled, double-blind phase III trial exploring the efficacy of the combination of letrozole plus temsirolimus as firstline hormonal therapy was closed on the basis of data from a planned interim analysis, showing that the trial was unlikely to achieve the targeted level of efficacy for the combination therapy compared with letrozole alone (Chow et al. 2006).

\section{Everolimus}

Everolimus is an oral mTOR inhibitor under clinical evaluation in different types of cancer. In preclinical models everolimus enhanced growth inhibition by trastuzumab and gefitinib in PTEN-deficient cells, overcoming resistance to these drugs (Lu et al. 2007, Bianco et al. 2008). Everolimus also inhibited estrogen-driven proliferation and increased the activity of letrozole in estrogen-dependent MCF-7 breast cancer cells (Boulay et al. 2005).

A pharmacodynamic phase I study showed that inhibition of mTOR signaling occurred at all dose levels and schedules in tumor and skin biopsies, being almost complete at $10 \mathrm{mg}$ daily and $50 \mathrm{mg}$ weekly (Tabernero et al. 2008). The most frequent toxicities were skin rash, stomatitis, headache, and fatigue. In a phase II neoadjuvant trial, everolimus (5 $\mathrm{mg}$ daily for 14 days) produced a significant decrease of Ki67 labeling index and phospho-AKT (pAKT) levels in 30 patients with breast cancer (Macaskill et al. 2006). High pretreatment pAKT correlated significantly with greater reductions in proliferation.

A phase II double-blind, randomized, placebocontrolled trial, evaluated the value of adding everolimus to letrozole as preoperative therapy of primary 
breast cancer in postmenopausal women (Baselga et al. 2009; Table 3). The study showed a higher response rate by palpation (primary endpoint) in the combination arm (68.1 vs $59.1 \%)$ that was also confirmed by ultrasound (58 vs $47 \%$ ). A biomarker analysis indicated a significant down-regulation between baseline and day 15 tumor biopsies for $\mathrm{pS} 6 \mathrm{~K}$ in response to everolimus (Gardner et al. 2007). Cell cycle response, as defined by proportion of patients with $\mathrm{Ki} 67 \leq 2$ at day 15 , was also significantly higher in the combination arm (57 vs 30\%, $P<0.01$ ). Most frequent severe toxicities related to everolimus were hyperglycemia, stomatitis, interstitial lung disease/pneumonitis, and infections.

\section{Farnesyl transferase inhibitors}

The most crucial modification involved in Ras activation is the covalent attachment of a farnesyl isoprenoid lipid to a cysteine residue in the $\mathrm{COOH}$ terminal of Ras proteins that is catalyzed by the enzyme farnesyl transferase (Downward 2003). However, many potential substrates, independent of Ras, have been identified for farnesyl transferase inhibitors (FTIs), such as lamin A and human perioxisomal farnesylated protein, both of which have been used as surrogate markers of farnesylation, RhoB, cyclic guanosine monophosphate phosphodiesterase $\alpha$, rhodopsin kinase and the $\gamma$ subunit of the retinal protein, transducin (O'Regan \& Khuri 2004). The oral FTIs currently in clinical development are tipifarnib, lonafarnib and AZD3409 (Table 1).

\section{Tipifarnib}

Preclinical studies have suggested a potential activity of tipifarnib in ER + breast cancer cells (Kelland et al. 2001). In addition, a synergistic anti-tumor effect of combination of tipifarnib and 4-hydroxytamoxifen was observed in ER + breast cancer cells (Martin et al. 2007).

Phase I studies of tipifarnib showed that continuous dosing was associated with severe toxicities, such as diarrhea, nausea, vomiting, renal dysfunction, and myelosuppression (O'Regan \& Khuri 2004). A phase II study evaluated the activity of tipifarnib, as single agent, in endocrine- and/or chemotherapy-resistant patients with metastatic breast cancer (Johnston et al. 2003). A total of 76 patients were treated with tipifarnib, either as a continuous dose of 300 or $400 \mathrm{mg}$ bis in die (BID; $n=41$ ) or an intermittent dose of $300 \mathrm{mg}$ BID for 21 days followed by 7 days off therapy $(n=35)$. In the continuous treatment arm, there were four partial responses $(10 \%)$ and six patients with stable disease $(15 \%)$ for at least 6 months. In the intermittent treatment arm, there were five partial responses (14\%) and three patients with stable disease (9\%). The incidence of hematological and neurological toxicities was significantly higher in the continuous treatment arm as compared with the intermittent arm. However, a randomized phase II trial of combination of tipifarnib and letrozole in postmenopausal women with ER + advanced breast cancer showed negative results for the combination that did not improve patients outcome, but was more toxic in terms of asymptomatic grade 3/4 neutropenia (Johnston et al. 2008b; Table 3).

\section{Lonafarnib}

Lonafarnib has shown anti-tumor activity in different models of human xenografts (Liu et al. 1998). In phase I trials, the dose limiting toxicity (DLT) was reached at 300-400 mg BID, depending on the schedule (continuous versus intermittent) and it was usually gastrointestinal (O'Regan \& Khuri 2004). Fatigue, which was severe at higher doses, and neutropenia were noted. Phase II studies of lonafarnib in combination with aromatase inhibitors (anastrozole) or trastuzumab plus chemotherapeutic agents (paclitaxel) are ongoing.

\section{AZD3409}

AZD3409 is a novel prenyl transferase inhibitor that was designed to mimic the C-terminal CAAX (CVIM: cysteine, valine, isoleucine, methionine) sequence of $\mathrm{K}-\mathrm{Ras} 4 \mathrm{~B}$, the Ras isoform most commonly mutated in human cancers (Stephens et al. 2003, Wakeling 2005). This compound has shown activity against both farnesyl transferase and geranylgeranyl transferase I in isolated enzyme studies. AZD3409 was able to inhibit the growth of tumor cells carrying either a mutated or wild-type Ras gene (Stephens et al. 2003, Khafagy et al. 2004). Interestingly, in preclinical studies it has been demonstrated that AZD3409 significantly affected the growth of gefitinib-resistant breast cancer cells (Maiello et al. 2007). Results of a phase I trial of AZD3409 in patients with advanced solid malignancies defined the MTD at $750 \mathrm{mg}$ BID in the fasted state (Appels et al. 2008). The dose-limiting toxicities were vomiting, diarrhea, and uncontrolled nausea. Pharmacodynamic studies also showed that farnesyl transferase was inhibited at all dose levels.

\section{Src inhibitors}

The role of Src in proliferation, invasion, angiogenesis, and metastasis supports the development of $\mathrm{Src}$ 
inhibitors in breast cancer. In fact, blockade of Src activation may slow disease progression in the metastatic disease and prevent the formation of metastases in the adjuvant setting. In this regard, several inhibitors of Src are in clinical development in breast cancer (Table 1).

\section{Dasatinib}

Dasatinib is an oral small molecule kinase inhibitor of both Src and Abl proteins (Lombardo et al. 2004), actually registered in the treatment of leukemia. Dasatinib inhibited the growth of different breast cancer cell lines, showing higher activity in cell lines belonging to the basal-subtype or that have undergone EMT (Finn et al. 2007, Huang et al. 2007). A set of three genes, moesin, caveolin-1, and YAP-1, whose elevated expression is associated with response to dasatinib was identified (Finn et al. 2007). A six gene signature including caveolin 1 and 2, annexin A1, EPH receptor A2, polymerase I, and transcript release factor and IGF binding protein 2, was also found to predict sensitivity to dasatinib (Huang et al. 2007). Interestingly, this gene signature was observed in basal-like breast tumors, thus confirming the potential sensitivity of this subtype of breast carcinoma to dasatinib (Huang et al. 2007).

The results of a phase I clinical trial of dasatinib in solid tumors showed no dose-limiting toxicity with an oral dose of 35, 50, or $70 \mathrm{mg}$ BID for 5 days followed by 2 days break, every week (Evans et al. 2005). A pharmacodynamic study showed that, on the BID regimen, Src phosphorylation was inhibited in a dosedependent manner, by assessing Src activation in PBMCs (Luo et al. 2006).

\section{AZD0530}

AZD0530 is an oral anilinoquinazoline with a high affinity and specificity for the tyrosine kinase domain of Src and Abl, that are inhibited at low nanomolar concentrations of the drug (Hennequin et al. 2006). In preclinical studies, AZD0530 was able to inhibit the anchorage-independent growth of MCF-7 breast cancer cells wild-type or stably expressing a mutant ER with increased sensitivity to estrogen (Herynk et al. 2006). However, these effects were reversed by estrogen. A cooperative inhibitory effect was also observed when ER + breast cancer cells were treated with a combination of AZD0530 and tamoxifen, suggesting that therapeutic use of this drug in ER+ breast cancer patients might require blockade of ER signaling (Herynk et al. 2006). AZD0530 also reduced motility and invasion of tamoxifen-resistant MCF-7 cells, and, in combination with tamoxifen, prevented the development of resistance to anti-estrogen therapy in MCF-7 cells (Hiscox et al. 2006). These findings provide a strong rationale for the development of AZD0530 in ER + breast cancer patients.

The results of a phase I and pharmacodynamic study of AZD0530 showed that the daily dose of $175 \mathrm{mg} /$ day is the MTD (Tabernero et al. 2007). DLTs occurred in three patients at $250 \mathrm{mg}$ (leukopenia, fatal septic shock with renal failure, asthenia) and in two patients at $200 \mathrm{mg}$ (febrile neutropenia and dyspnea). A consistent modulation of phosphorylation and/or cellular localization of tumor paxillin and FAK, two targets of Src tyrosine kinase, were observed in patients treated with AZD0530. Finally, AZD0530 therapy produced a significant decrease in markers of osteoclast-mediated bone resorption with a dose-response trend.

\section{Bosutinib}

Bosutinib is an orally active inhibitor of $\mathrm{Abl}$ and $\mathrm{Src}$ kinases. Treatment of MDA-MB-231 breast cancer cells with bosutinib produced a marked inhibition of cell proliferation, invasion, and migration, as well as a significant inhibition of MAPK and AKT activation (Jallal et al. 2007). In a phase I study, the MTD was found at $500 \mathrm{mg} /$ day once daily (Messersmith et al. 2007). However, the recommended dose for phase II studies was $400 \mathrm{mg}$, due to significant grade 2 gastrointestinal toxicity observed in patients treated with $500 \mathrm{mg}$. The most frequent adverse effects were nausea, diarrhea, anorexia, asthenia, and vomiting. Stabilization of the disease for more than 24 weeks was observed in $3 / 51$ patients, including one breast cancer patient.

\section{Inhibitors of MEK signaling}

A number of MEK inhibitors are in preclinical and clinical development in different tumor types. Data in breast cancer are available only for AZD6244 (ARRY142886), an highly specific MEK $1 / 2$ inhibitor that binds to the allosteric inhibitor-binding site and locks MEK1/2 in an inactive conformation (Table 1; Yeh et al. 2007). Preclinical studies have shown that tumor cells carrying activating Ras and/or B-Raf mutations are more sensitive to AZD6244 as compared with those possessing wild-type genes (Davies et al. 2007, Yeh et al. 2007). However, AZD6244 inhibited the in vivo growth of ZR-75-1 xenografts, which carry wildtype Ras and Raf genes, despite little effects on cell viability in vitro. The efficacy of AZD6244 in this tumor model might be due to inhibition of angiogenesis and/or 
to increased dependency of tumor cells from MEK activation for their in vivo growth (Yeh et al. 2007).

A phase I clinical trial showed that AZD6244 orally was well tolerated up to $100 \mathrm{mg}$ BID in patients with solid tumor, including breast cancer. The most frequent side effects were acneiform rash, diarrhea, nausea, and fatigue (Adjei et al. 2008). Complete inhibition of pMAPK phosphorylation in PBMCs was observed $1 \mathrm{~h}$ after drug administration and was maintained during therapy. Analyses of paired tumor samples collected before and after treatment showed that treatment with AZD6244 produced a significant inhibition of MAPK phosphorylation in tumor tissue. Ki-67 labeling index was also reduced in these samples but not as consistently as pMAPK. The best clinical response was stable disease, lasted for 5 or more months in $16 \%$ of patients. No correlation was found between activity of AZD6244 and mutational status of RAS or Raf.

\section{Inhibitors of PKC}

Enzastaurin is an orally available, potent inhibitor of PKC $\beta$, which also inhibits other PKC isoenzymes, although at higher concentration as compared with PKC $\beta$ (Table 1; Graff et al. 2005). By blocking PKC activation, enzastaurin inhibits AKT and GSK3 $\beta$ activation, suppresses tumor cell proliferation, induces tumor cell death and inhibits VEGF-mediated angiogenesis. A phase I study showed that enzastaurin was well tolerated at doses up to $700 \mathrm{mg}$ daily. No MTD was established and the recommended phase II dose was $525 \mathrm{mg} /$ day, based on plasma levels inhibiting PKC $\beta$ (Carducci et al. 2006). Moreover, evidence of early activity in terms of stable disease was observed. However, no clinical activity was reported in a phase II study of enzastaurin as single agent in patients with metastatic breast cancer previously treated with anthracyclines and taxanes (Krop et al. 2008). Phase II studies are currently ongoing to evaluate the combination of enzastaurin with chemotherapy (capecitabine, paclitaxel), hormonal therapy (fulvestrant) or other targeted therapies (bevacizumab) in breast cancer.

\section{Conclusions and future perspectives}

The development of target-based agents in breast cancer has been characterized up to now by rather few successes and several failures. As matter of fact, the target-based agents that have shown significant clinical activity in breast cancer patients up to now are the antiErbB-2 drugs trastuzumab and lapatinib, and the antiVEGF mAb bevacizumab. Interestingly, all these drugs have been approved for treatment of breast cancer patients in association with chemotherapy. Only trastuzumab and lapatinib have also shown activity as single agents.

It might be argued that target-based agents are active when their targets play a key role in tumor growth, such as ErbB-2 in breast tumors that overexpress this receptor. However, it must be emphasized that the majority of ErbB-2 positive patients have mechanisms of resistance to trastuzumab at diagnosis. In fact, only $30 \%$ of patients with advanced ErbB-2-positive breast cancer respond to trastuzumab as first-line therapy, and the response rate drops to $15 \%$ in pretreated patients. Furthermore, almost all patients will become resistant to the drug during the course of the treatment. Therefore, the main question that we need to address in order to improve this therapeutic approach is why tumors do not respond to target-based agents.

Cancer is the result of several, different genetic, and epigenetic alterations. Simultaneous activation of different oncogenic pathways has been shown in breast cancer cells, and these pathways are likely to cooperate in sustaining the proliferation and the survival of breast cancer cells. Resistance to treatment with target-based agents is, therefore, the consequence of the complex mechanisms that regulate the growth of breast tumors. It is possible that a minority of tumors depend on the activation of a single pathway ('oncogenic addiction'), as shown for some ErbB-2 of ER positive tumors. However, evidence suggests that the majority of the tumors have a network of different aberrantly activated signaling pathways, and they unlikely will respond to the blockade of a single oncogene.

The activation of signaling pathways in breast cancer cells might be significantly altered by treatment with anti-cancer agents, including target-based agents and endocrine therapies. In fact, a number of studies have shown that breast cancer cells are able to escape the activity of target-based agents by developing adaptive mechanisms that lead to activation of alternative pathways involved in the proliferation and survival of tumor cells (Jones et al. 2004, Xia et al. 2006, Sergina et al. 2007, Normanno et al. 2008). The results of preclinical and clinical studies also suggest that heterogenous patterns of resistance might occur. For example, resistance to EGFR-TKIs in breast cancer has been linked to activation of ErbB-2/ErbB-3/AKT signaling, to persistent activation of MAPK or even to mutations of ErbB-2, depending on the background of the cell lines used, on the duration of exposure to the drugs and possibly other factors (Piechocki et al. 2007, Sergina et al. 2007, Normanno et al. 2008). The development of high throughput technologies is also 


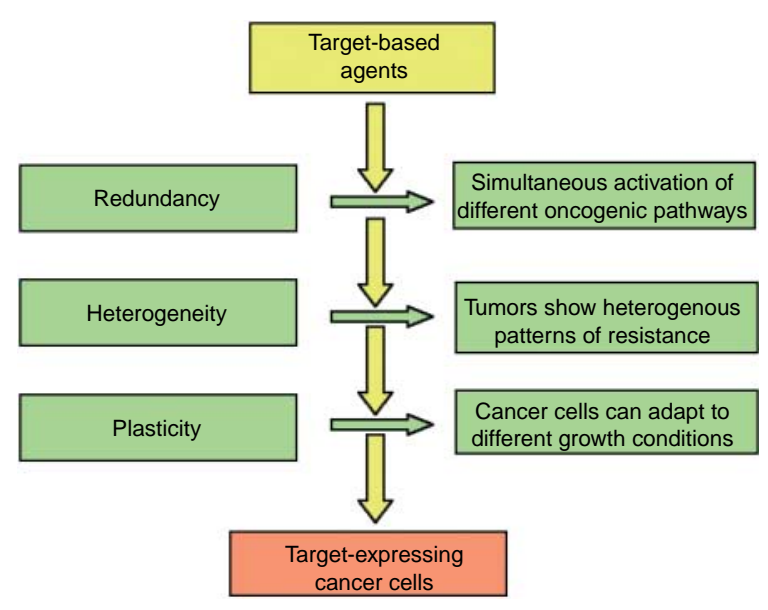

Figure 2 Redundancy, heterogeneity, and plasticity that lead tumor cells to resistance to signaling inhibitors in breast cancer.

revealing that acquired resistance is frequently a complex phenomenon. Gene expression profiling of both fulvestrant- and tamoxifen-resistant breast cancer cells showed that resistance to endocrine therapy is characterized by significant up-regulation of multiple growth-stimulatory pathways (Fan et al. 2006). Finally, the pathways of resistance can change during the time. For example, tamoxifen-resistant breast cancer cells are extremely sensitive to gefitinib (Knowlden et al. 2003). However, prolonged exposure to gefitinib led to the development of resistance to this latter drug through the activation of an IGF-1R dependent mechanism (Jones et al. 2004). Taken together, the above-mentioned findings suggest that the redundancy of oncogenic pathways activated in cancer cells, the heterogeneity of the mechanisms of resistance that have been found among primary tumors and cell lines, and the plasticity of tumor cells that are capable to adapt to different growth conditions, significantly hamper the efficacy of each signaling inhibitor in breast cancer (Fig. 2).

Increasing evidence suggests that cancer stem cells might be resistant to chemotherapy and therefore responsible for cancer relapse (Zhang \& Rosen 2006). Recently, a neoadjuvant trial in breast cancer patients has shown that the percentage of putative cancer stem cells increased following treatment with chemotherapy, providing evidence supporting their intrinsic chemoresistance ( $\mathrm{Li}$ et al. 2008). Interestingly, in the same trial it was found that lapatinib treatment of patients with ErbB-2 positive tumors did not lead to an increase in the percentage of cancer stem cells, suggesting that lapatinib treatment could eliminate ErbB-2 positive cancer stem cells. These preliminary observations support the hypothesis that addition of specific target-based agents to chemotherapy might lead to killing of cancer stem cells. In this regard, the molecular profiling of cancer stem cells will provide information that will be useful for the development of novel therapeutic strategies in which signaling pathways that are critical for their survival will be targeted.

The above-summarized information indicates that the molecular characterization of the tumors of each individual patient and the identification of biological markers that are associated with response or resistance to treatment are mandatory to improve the efficacy of target-based agents in breast cancer. An example comes, again, from lapatinib for which a six gene signature predictor of response to lapatinib has been identified (Gray et al. 2008). In addition, gene signatures that are correlated with the response/resistance to the src inhibitor dasatinib have been developed and might turn useful to select patients to be treated with this drug (Finn et al. 2007, Huang et al. 2007). Finally, gene signatures associated with the activation of specific signaling pathways are being developed, and they might allow in the future to identify the signaling pathways that are specifically activated in each individual tumor (Bild et al. 2006).

Although the majority of the target-based agents evaluated up to now failed to show significant clinical activity, it is likely that these agents might contribute to control breast cancer progression in the context of combinations of compounds targeting different signaling pathways that cooperate in sustaining the growth of breast tumor cells. Agents with a broader spectrum of action, such as histone deacetylase inhibitors and proteasome inhibitors that are in the initial phase of development in breast cancer, might also turn to be effective in this strategy. The high cost of target-based agents, the potential toxicity of their combinations and the complexity and relatively elevated costs of highthroughput technologies that are required to provide a molecular portrait of breast tumors are the limitations that scientists will have to face to develop this new therapeutic approach.

\section{Declaration of interest}

The authors declare no potential conflicts of interest.

\section{Funding}

This work was partially supported, through research grants, by the nonprofit 'Associazione Italiana per la Ricerca sul Cancro' (AIRC) and Ministero della Salute to N N and F P. 


\section{References}

Abrams TJ, Murray LJ, Pesenti E, Holway VW, Colombo T, Lee LB, Cherrington JM \& Pryer NK 2003 Preclinical evaluation of the tyrosine kinase inhibitor SU11248 as a single agent and in combination with "standard of care" therapeutic agents for the treatment of breast cancer. Molecular Cancer Therapeutics 2 1011-1021.

Adjei AA, Cohen RB, Franklin W, Morris C, Wilson D, Molina JR, Hanson LJ, Gore L, Chow L, Leong S et al. 2008 Phase I pharmacokinetic and pharmacodynamic study of the oral, small-molecule mitogen-activated protein kinase kinase 1/2 inhibitor AZD6244 (ARRY142886) in patients with advanced cancers. Journal of Clinical Oncology 26 2139-2146.

Albain KS, Elledge R, Gradishar WJ, Hayes DF, Rowinsky E, Hudis C, Pusztai L, Tripathy D, Modi S \& Rubi S 2002 Open-label, phase II. multicenter trial of ZD1839 ('Iressa') in patients with advanced breast cancer. Breast Cancer Research and Treatment 76 S33.

Ali IU, Schriml LM \& Dean M 1999 Mutational spectra of PTEN/MMAC1 gene: a tumor suppressor with lipid phosphatase activity. Journal of the National Cancer Institute 91 1922-1932.

Appels NM, Bolijn MJ, Chan K, Stephens TC, Hoctin-Boes G, Middleton M, Beijnen JH, de Bono JS, Harris AL \& Schellens JH 2008 Phase I pharmacokinetic and pharmacodynamic study of the prenyl transferase inhibitor AZD3409 in patients with advanced cancer. British Journal of Cancer 98 1951-1958.

Bartsch R, Wenzel C, Hussian D, Pluschnig U, Sevelda U, Koestler W, Altorjai G, Locker GJ, Mader R, Zielinski CC et al. 2006 Analysis of trastuzumab and chemotherapy in advanced breast cancer after the failure of at least one earlier combination: an observational study. $B M C$ Cancer 663.

Bartsch R, Wenzel C, Altorjai G, Pluschnig U, Rudas M, Mader RM, Gnant M, Zielinski CC \& Steger GG 2007 Capecitabine and trastuzumab in heavily pretreated metastatic breast cancer. Journal of Clinical Oncology 25 3853-3858.

Bartsch R, Wenzel C, Gampenrieder SP, Pluschnig U, Altorjai G, Rudas M, Mader RM, Dubsky P, Rottenfusser A, Gnant M et al. 2008 Trastuzumab and gemcitabine as salvage therapy in heavily pre-treated patients with metastatic breast cancer. Cancer Chemotherapy and Pharmacology 62 903-910.

Baselga J, Tripathy D, Mendelsohn J, Baughman S, Benz CC, Dantis L, Sklarin NT, Seidman AD, Hudis CA, Moore J et al. 1999 Phase II study of weekly intravenous trastuzumab (Herceptin) in patients with HER2/neuoverexpressing metastatic breast cancer. Seminars in Oncology 26 78-83.

Baselga J, Albanell J, Ruiz A, Lluch A, Gascon P, Guillem V, Gonzalez S, Sauleda S, Marimon I, Tabernero JM et al.
2005 Phase II and tumor pharmacodynamic study of gefitinib in patients with advanced breast cancer. Journal of Clinical Oncology 23 5323-5333.

Baselga J, Semiglazov V, van Dam P, Manikhas A, Bellet M, Mayordomo J, Campone M, Kubista E, Greil R, Bianchi G et al. 2009 Phase II randomized study of neoadjuvant everolimus plus letrozole compared with placebo plus letrozole in patients with estrogen receptor-positive breast cancer. Journal of Clinical Oncology 27 2630-2637.

Bianco R, Garofalo S, Rosa R, Damiano V, Gelardi T, Daniele G, Marciano R, Ciardiello F \& Tortora G 2008 Inhibition of mTOR pathway by everolimus cooperates with EGFR inhibitors in human tumours sensitive and resistant to anti-EGFR drugs. British Journal of Cancer 98 923-930.

Bild AH, Yao G, Chang JT, Wang Q, Potti A, Chasse D, Joshi MB, Harpole D, Lancaster JM, Berchuck A et al. 2006 Oncogenic pathway signatures in human cancers as a guide to targeted therapies. Nature 439 353-357.

Bjornsti MA \& Houghton PJ 2004 The TOR pathway: a target for cancer therapy. Nature Reviews. Cancer 4 335-348.

Blackwell KL, Burstein H, Pegram M, Storniolo AM, Salazar VM, Maleski JE, Lin X, Spector N, Stein SH \& Berger MS 2005 Determining relevant biomarkers from tissue and serum that may predict response to single agent lapatinib in trastuzumab refractory metastatic breast cancer. Journal of Clinical Oncology 23 (Supplement 16S part I) abstract 3004.

Boer K, Lang I, Llombart-Cussac A, Andreasson I, Vivanco G, Sanders N, Pover G \& Murray E 2007 Vandetanib with docetaxel as second-line treatment for advanced breast cancer: a double-blind, placebo-controlled, randomized phase II study. San Antonio Breast Cancer Symposium abstract 6081.

Bos JL 1989 Ras oncogenes in human cancer: a review. Cancer Research 49 4682-4689.

Boulay A, Rudloff J, Ye J, Zumstein-Mecker S, O'Reilly T, Evans DB, Chen S \& Lane HA 2005 Dual inhibition of $\mathrm{mTOR}$ and estrogen receptor signaling in vitro induces cell death in models of breast cancer. Clinical Cancer Research 11 5319-5328.

Del Bufalo D, Ciuffreda L, Trisciuoglio D, Desideri M, Cognetti F, Zupi G \& Milella M 2006 Antiangiogenic potential of the mammalian target of rapamycin inhibitor temsirolimus. Cancer Research 66 5549-5554.

Burris H III, Yardley D, Jones S, Houston G, Broome C, Thompson D, Greco FA, White M \& Hainsworth J 2004 Phase II trial of trastuzumab followed by weekly paclitaxel/carboplatin as first-line treatment for patients with metastatic breast cancer. Journal of Clinical Oncology 22 1621-1629.

Burris HA III, Hurwitz HI, Dees EC, Dowlati A, Blackwell KL, O’Neil B, Marcom PK, Ellis MJ, Overmoyer B, 
Jones SF et al. 2005 Phase I safety, pharmacokinetics, and clinical activity study of lapatinib (GW572016) a reversible dual inhibitor of epidermal growth factor receptor tyrosine kinases, in heavily pretreated patients with metastatic carcinomas. Journal of Clinical Oncology 23 5305-5313.

Burstein HJ, Kuter I, Campos SM, Gelman RS, Tribou L, Parker LM, Manola J, Younger J, Matulonis U, Bunnell CA et al. 2001 Clinical activity of trastuzumab and vinorelbine in women with HER2-overexpressing metastatic breast cancer. Journal of Clinical Oncology 19 2722-2730.

Burstein HJ, Harris LN, Marcom PK, Lambert-Falls R, Havlin K, Overmoyer B, Friedlander RJ Jr, Gargiulo J, Strenger R, Vogel CL et al. 2003 Trastuzumab and vinorelbine as first-line therapy for HER2-overexpressing metastatic breast cancer: multicenter phase II trial with clinical outcomes, analysis of serum tumor markers as predictive factors, and cardiac surveillance algorithm. Journal of Clinical Oncology 21 2889-2895.

Burstein HJ, Elias AD, Rugo HS, Cobleigh MA, Wolff AC, Eisenberg PD, Lehman M, Adams BJ, Bello CL, DePrimo SE et al. 2008a Phase II study of sunitinib malate, an oral multitargeted tyrosine kinase inhibitor, in patients with metastatic breast cancer previously treated with an anthracycline and a taxane. Journal of Clinical Oncology 26 1810-1816.

Burstein HJ, Storniolo AM, Franco S, Forster J, Stein S, Rubin S, Salazar VM \& Blackwell KL $2008 b$ A phase II study of lapatinib monotherapy in chemotherapyrefractory HER2-positive and HER2-negative advanced or metastatic breast cancer. Annals of Oncology 19 1068-1074.

Camirand A, Zakikhani M, Young F \& Pollak M 2005 Inhibition of insulin-like growth factor-1 receptor signaling enhances growth-inhibitory and proapoptotic effects of gefitinib (Iressa) in human breast cancer cells. Breast Cancer Research 7 R570-R579.

Campiglio M, Locatelli A, Olgiati C, Normanno N, Somenzi G, Vigano L, Fumagalli M, Menard S \& Gianni L 2004 Inhibition of proliferation and induction of apoptosis in breast cancer cells by the epidermal growth factor receptor (EGFR) tyrosine kinase inhibitor ZD1839 ('Iressa') is independent of EGFR expression level. Journal of Cellular Physiology 198 259-268.

Carducci MA, Musib L, Kies MS, Pili R, Truong M, Brahmer JR, Cole P, Sullivan R, Riddle J, Schmidt J et al. 2006 Phase I dose escalation and pharmacokinetic study of enzastaurin, an oral protein kinase $\mathrm{C}$ beta inhibitor, in patients with advanced cancer. Journal of Clinical Oncology 24 4092-4099.

Carey LA, Rugo HS, Marcom PK, Irvin W, Ferraro M, Burrows E, He X, Perou CM \& Winer EP 2008 TBCRC001: EGFR inhibition with cetuximab added to carboplatin in metastatic triple-negative (basal-like) breast cancer. Journal of Clinical Oncology 26 (Supplement) abstract 1009.

Carpenter JT, Roche H, Campone M, Colomer R, JagielloGruszfeld A, Moore L, D'Amore M, Kong S, Boni J \& Baselga J 2005 Randomized 3-arm, phase 2 study of temsirolimus (CCI-779) in combination with letrozole in postmenopausal women with locally advanced or metastatic breast cancer. Journal of Clinical Oncology 23 (Supplement 16S part I) abstract 564.

Chan S, Scheulen ME, Johnston S, Mross K, Cardoso F, Dittrich C, Eiermann W, Hess D, Morant R, Semiglazov V et al. 2005 Phase II study of temsirolimus (CCI-779), a novel inhibitor of mTOR, in heavily pretreated patients with locally advanced or metastatic breast cancer. Journal of Clinical Oncology 23 5314-5322.

Chow LQ \& Eckhardt SG 2007 Sunitinib: from rational design to clinical efficacy. Journal of Clinical Oncology 25 884-896.

Chow LWC, Sun Y, Jassem J, Baselga J, Hayes DF, Wolff AC, Hachemi S, Cincotta M, Yu BW, Kong S et al. 2006 Phase 3 study of temsirolimus with letrozole or letrozole alone in postmenopausal women with locally advanced or metastatic breast cancer. Breast Cancer Research and Treatment 100 (Supplement 1) abstract 6091.

Chu I, Blackwell K, Chen S \& Slingerland J 2005 The dual ErbB1/ErbB2 inhibitor, lapatinib (GW572016) cooperates with tamoxifen to inhibit both cell proliferationand estrogen-dependent gene expression in antiestrogenresistant breast cancer. Cancer Research 65 18-25.

Ciardiello F \& Tortora G 2008 EGFR antagonists in cancer treatment. New England Journal of Medicine 358 1160-1174.

Ciardiello F, Caputo R, Damiano V, Caputo R, Troiani T, Vitagliano D, Carlomagno F, Veneziani BM, Fontanini G, Bianco AR et al. 2003 Antitumor effects of ZD6474, a small molecule vascular endothelial growth factor receptor tyrosine kinase inhibitor, with additional activity against epidermal growth factor receptor tyrosine kinase. Clinical Cancer Research 9 1546-1556.

Ciardiello F, Bianco R, Caputo R, Caputo R, Damiano V, Troiani T, Melisi D, De Vita F, De Placido S, Bianco AR et al. 2004 Antitumor activity of ZD6474, a vascular endothelial growth factor receptor tyrosine kinase inhibitor, in human cancer cells with acquired resistance to antiepidermal growth factor receptor therapy. Clinical Cancer Research 10 784-793.

Ciardiello F, Troiani T, Caputo F, De Laurentiis M, Tortora G, Palmieri G, De Vita F, Diadema MR, Orditura M, Colantuoni G et al. 2006 Phase II study of gefitinib in combination with docetaxel as first-line therapy in metastatic breast cancer. British Journal of Cancer 94 1604-1609.

Cobleigh MA, Vogel CL, Tripathy D, Robert NJ, Scholl S, Fehrenbacher L, Wolter JM, Paton V, Shak S, Lieberman 
G et al. 1999 Multinational study of the efficacy and safety of humanized anti-HER2 monoclonal antibody in women who have HER2-overexpressing metastatic breast cancer that has progressed after chemotherapy for metastatic disease. Journal of Clinical Oncology 17 2639-2648.

Cobleigh MA, Langmuir VK, Sledge GW, Miller KD, Haney L, Novotny WF, Reimann JD \& Vassel A 2003 A phase I/II dose-escalation trial of bevacizumab in previously treated metastatic breast cancer. Seminars in Oncology 30 117-124.

Cristofanilli M, Valero V, Mangalik A, Rabinowitz I, Arena FP, Kroener JF, Curcio E, Watkins C \& Magill P 2008 A phase II multicenter, double-blind, randomized trial to compare anastrozole plus gefinitib with anastrozole plus placebo in postmenopausal women with hormone receptor-positive $(\mathrm{HR}+)$ metastatic breast cancer (MBC). Journal of Clinical Oncology 26 (Supplement) abstract 1012.

Crowder RJ \& Ellis MJ 2005 Treating breast cancer through novel inhibitors of the phosphatidylinositol 3'-kinase pathway. Breast Cancer Research 7 212-214.

Davies BR, Logie A, McKay JS, Martin P, Steele S, Jenkins R, Cockerill M, Cartlidge S \& Smith PD 2007 AZD6244 (ARRY-142886), a potent inhibitor of mitogen-activated protein kinase/extracellular signalregulated kinase kinase 1/2 kinases: mechanism of action in vivo, pharmacokinetic/pharmacodynamic relationship, and potential for combination in preclinical models. Molecular Cancer Therapeutics 6 2209-2219.

deGraffenried LA, Friedrichs WE, Russell DH, Donzis EJ, Middleton AK, Silva JM, Roth RA \& Hidalgo M 2004 Inhibition of mTOR activity restores tamoxifen response in breast cancer cells with aberrant Akt Activity. Clinical Cancer Research 10 8059-8067.

Demonty G, Bernard-Marty C, Puglisi F, Mancini I \& Piccart M 2007 Progress and new standards of care in the management of HER-2 positive breast cancer. European Journal of Cancer 43497.

Dickler MN, Cobleigh MA, Miller KD, Klein PM \& Winer EP 2009 Efficacy and safety of erlotinib in patients with locally advanced or metastatic breast cancer. Breast Cancer Research and Treatment 115 115-121.

DiGiovanna MP, Stern DF, Edgerton SM, Whalen SG, Moore D II \& Thor AD 2005 Relationship of epidermal growth factor receptor expression to ErbB-2 signaling activity and prognosis in breast cancer patients. Journal of Clinical Oncology 23 1152-1160.

Dimri M, Naramura M, Duan L, Chen J, Ortega-Cava C, Chen G, Goswami R, Fernandes N, Gao Q, Dimri GP et al. 2007 Modeling breast cancer-associated c-Src and EGFR overexpression in human MECs: c-Src and EGFR cooperatively promote aberrant three-dimensional acinar structure and invasive behavior. Cancer Research 67 4164-4172.
Downward J 2003 Targeting RAS signalling pathways in cancer therapy. Nature Reviews. Cancer 3 11-22.

Dunn KL, Espino PS, Drobic B, He S \& Davie JR 2005 The Ras-MAPK signal transduction pathway, cancer and chromatin remodeling. Biochemistry and Cell Biology 83 1-14.

Ebos JM, Lee CR, Cruz-Munoz W, Bjarnason GA, Christensen JG \& Kerbel RS 2009 Accelerated metastasis after short-term treatment with a potent inhibitor of tumor angiogenesis. Cancer Cell 15 232-239.

Evans TRJ, Morgan JA, van den Abbeele AD, McPherson IRJ, George S, Crawford D, Mastrullo JM, Cheng S, Fletcher JA \& Demetri GD 2005 Phase I dose-escalation study of the SRC and multi-kinase inhibitor BMS-354825 in patients (pts) with GIST and other solid tumors. Journal of Clinical Oncology 23 (Supplement 16S part I) abstract 3034.

Fan M, Yan PS, Hartman-Frey C, Chen L, Paik H, Oyer SL, Salisbury JD, Cheng ASL, Li L, Abbosh PH et al. 2006 Diverse gene expression and DNA methylation profiles correlate with differential adaptation of breast cancer cells to the antiestrogens tamoxifen and fulvestrant. Cancer Research 66 11954-11966.

Ferrara N \& Kerbel RS 2005 Angiogenesis as a therapeutic target. Nature 438 967-974.

Finn RS, Dering J, Ginther C, Wilson CA, Glaspy P, Tchekmedyian N \& Slamon DJ 2007 Dasatinib, an orally active small molecule inhibitor of both the src and abl kinases, selectively inhibits growth of basal-type/"triplenegative" breast cancer cell lines growing in vitro. Breast Cancer Research and Treatment 105 319-326.

Forbes S, Clements J, Dawson E, Bamford S, Webb T, Dogan A, Flanagan A, Teague J, Wooster R, Futreal PA et al. 2006 Cosmic 2005. British Journal of Cancer 94 318-322.

Forero-Torres A, Galleshaw J, Jones C, Percent I, Nabell L, Carpenter J, Falkson C, Krontiras H, Bland K, De Los Santos J et al. 2008 A pilot open-label trial of preoperative (neoadjuvant) letrozole in combination with bevacizumab in postmenopausal women with newly diagnosed operable breast cancer. Journal of Clinical Oncology 26 (abstr 625).

Fountzilas G, Razis E, Tsavdaridis D, Karina M, Labropoulos S, Christodoulou C, Mavroudis D, Gogas H, Georgoulias V \& Skarlos D 2003 Continuation of trastuzumab beyond disease progression is feasible and safe in patients with metastatic breast cancer: a retrospective analysis of 80 cases by the hellenic cooperative oncology group. Clinical Breast Cancer 4 120-125.

Fountzilas G, Pectasides D, Kalogera-Fountzila A, Skarlos D, Kalofonos HP, Papadimitriou C, Bafaloukos D, Lambropoulos S, Papadopoulos S, Kourea H et al. 2005 Paclitaxel and carboplatin as first-line chemotherapy combined with gefitinib (IRESSA) in patients with advanced breast cancer: a phase I/II study conducted by the Hellenic Cooperative Oncology Group. Breast Cancer Research and Treatment 92 1-9. 
Fujimoto-Ouchi K, Sekiguchi F \& Kazushige M 2005 Preclinical study of continuous administration of trastuzumab as combination therapy after disease progression with trastuzumab monotherapy. Proceedings of the American Association for Cancer Research 46 abstract 5062.

Gardner H, Bandaru R, Barrett C, Calcaterra M, Crowell T, Decker J, Dixon M, Fisch R, Fuchs M, Gelb A et al. 2007 Biomarker analysis of a phase II double-blind randomized trial of daily oral RAD001(everolimus) plus letrozole as neoadjuvant therapy for patients with estrogen receptor positive breast cancer. San Antonio Breast Cancer Symposium abstract 4006.

Gasparini G, Gion M, Mariani L, Papaldo P, Crivellari D, Filippelli G, Morabito A, Silingardi V, Torino F, Spada A et al. 2007 Randomized phase II trial of weekly paclitaxel alone versus trastuzumab plus weekly paclitaxel as firstline therapy of patients with Her-2 positive advanced breast cancer. Breast Cancer Research and Treatment 101 355-365.

Gee JM, Harper ME, Hutcheson IR, Madden TA, Barrow D, Knowlden JM, McClelland RA, Jordan N, Wakeling AE \& Nicholson RI 2003 The antiepidermal growth factor receptor agent gefitinib (ZD1839/Iressa) improves antihormone response and prevents development of resistance in breast cancer in vitro. Endocrinology 144 5105-5117.

Gelmon KA, Mackey J, Verma S, Gertler SZ, Bangemann N, Klimo P, Schneeweiss A, Bremer K, Soulieres D, Tonkin K et al. 2004 Use of trastuzumab beyond disease progression: observations from a retrospective review of case histories. Clinical Breast Cancer 5 52-58 (discussion 59-62).

Gelmon KA, Fumoleau P, Verma S, Wardley AM, Conte PF, Miles D, Gianni L, McNally VA, Ross G \& Baselga J 2008 Results of a phase II trial of trastuzumab $(\mathrm{H})$ and pertuzumab (P) in patients (pts) with HER2-positive metastatic breast cancer (MBC) who had progressed during trastuzumab therapy. Journal of Clinical Oncology 26 (Supplement) abstract 1026.

Geyer CE, Forster J, Lindquist D, Chan S, Romieu CG, Pienkowski T, Jagiello-Gruszfeld A, Crown J, Chan A, Kaufman B et al. 2006 Lapatinib plus capecitabine for HER2-positive advanced breast cancer. New England Journal of Medicine 355 2733-2743.

Gordge PC, Hulme MJ, Clegg RA \& Miller WR 1996 Elevation of protein kinase A and protein kinase $\mathrm{C}$ activities in malignant as compared with normal human breast tissue. European Journal of Cancer 32A 2120-2126.

Gordon MS, Margolin K, Talpaz M, Sledge GW Jr, Holmgren E, Benjamin R, Stalter S, Shak S \& Adelman D 2001 Phase I safety and pharmacokinetic study of recombinant human anti-vascular endothelial growth factor in patients with advanced cancer. Journal of Clinical Oncology 19 843-850.
Graff JR, McNulty AM, Hanna KR, Konicek BW, Lynch RL, Bailey SN, Banks C, Capen A, Goode R, Lewis JE et al. 2005 The protein kinase $\mathrm{C}\{$ beta $\}$-selective inhibitor, enzastaurin (LY317615.HCl), suppresses signaling through the AKT pathway, induces apoptosis, and suppresses growth of human colon cancer and glioblastoma xenografts. Cancer Research 65 7462-7469.

Gray JW, Das D, Wang N, Kuo W, Press MF, Di Leo A, Ellis C, Arbushites M, Williams L \& Koehler M 2008 Identification of a 6 gene molecular predictor of lapatinib related benefit: from breast cancer cell lines to a phase III trial. Journal of Clinical Oncology 261043.

Guix M, Granja Nde M, Meszoely I, Adkins TB, Wieman BM, Frierson KE, Sanchez V, Sanders ME, Grau AM, Mayer IA et al. 2008 Short preoperative treatment with erlotinib inhibits tumor cell proliferation in hormone receptor-positive breast cancers. Journal of Clinical Oncology 26 897-906.

Hennequin LF, Allen J, Breed J, Curwen J, Fennell M, Green TP, Lambert-van der Brempt C, Morgentin R, Norman RA, Olivier A et al. 2006 N-(5-chloro-1,3benzodioxol-4-yl)-7-[2-(4-methylpiperazin-1-yl)ethoxy]5- (tetrahydro-2H-pyran-4-yloxy)quinazolin-4-amine, a novel, highly selective, orally available, dual-specific c-Src/Abl kinase inhibitor. Journal of Medicinal Chemistry 49 6465-6488.

Herynk MH, Beyer AR, Cui Y, Weiss H, Anderson E, Green TP \& Fuqua SA 2006 Cooperative action of tamoxifen and c-Src inhibition in preventing the growth of estrogen receptor-positive human breast cancer cells. Molecular Cancer Therapeutics 5 3023-3031.

Hiscox S, Morgan L, Green TP, Barrow D, Gee J \& Nicholson RI 2006 Elevated Src activity promotes cellular invasion and motility in tamoxifen resistant breast cancer cells. Breast Cancer Research and Treatment 97 263-274.

Hobday TJ, Stella PJ, Fitch TR, Jaslowski A, LaPlant B, Ames MM, Goetz MP \& Perez EA 2008 A phase II trial of irinotecan plus cetuximab in patients with metastatic breast cancer and prior anthracycline and/or taxanecontaining therapy. Journal of Clinical Oncology 26 (Supplement) abstract 1081.

Hollestelle A, Elstrodt F, Nagel JH, Kallemeijn WW \& Schutte M 2007 Phosphatidylinositol-3-OH kinase or RAS pathway mutations in human breast cancer cell lines. Molecular Cancer Research 5 195-201.

Huang F, Reeves K, Han X, Fairchild C, Platero S, Wong TW, Lee F, Shaw P \& Clark E 2007 Identification of candidate molecular markers predicting sensitivity in solid tumors to dasatinib: rationale for patient selection. Cancer Research 67 2226-2238.

Hurwitz H, Dowlati A, Savage S, Fernando N, Lasalvia S, Whitehead B, Suttle B, Collins D, Ho P \& Pandite L 2005 Safety, tolerability and pharmacokinetics of oral administration of GW786034 in pts with solid tumors. Journal of Clinical Oncology 23 (Supplement 16S part I) abstract 3012 . 
Inai T, Mancuso M, Hashizume H, Baffert F, Haskell A, Baluk P, Hu-Lowe DD, Shalinsky DR, Thurston G, Yancopoulos GD et al. 2004 Inhibition of vascular endothelial growth factor (VEGF) signaling in cancer causes loss of endothelial fenestrations, regression of tumor vessels, and appearance of basement membrane ghosts. American Journal of Pathology 165 35-52.

Irby RB \& Yeatman TJ 2000 Role of Src expression and activation in human cancer. Oncogene 19 5636-5642.

Jallal H, Valentino M-L, Chen G, Boschelli F, Ali S \& Rabbani SA 2007 A Src/Abl kinase inhibitor, SKI-606, blocks breast cancer invasion, growth, and metastasis in vitro and in vivo. Cancer Research 67 1580-1588.

Joensuu H, Kellokumpu-Lehtinen PL, Bono P, Alanko T, Kataja V, Asola R, Utriainen T, Kokko R, Hemminki A, Tarkkanen M et al. 2006 Adjuvant docetaxel or vinorelbine with or without trastuzumab for breast cancer. New England Journal of Medicine 354 809-820.

Johnston SR, Hickish T, Ellis P, Houston S, Kelland L, Dowsett M, Salter J, Michiels B, Perez-Ruixo JJ, Palmer P et al. 2003 Phase II study of the efficacy and tolerability of two dosing regimens of the farnesyl transferase inhibitor, R115777, in advanced breast cancer. Journal of Clinical Oncology 21 2492-2499.

Johnston S, Pegram M, Press M, Pippen J, Pivot X, Gomez H, Florance A, O'Rourke L \& Maltzman J 2008a Lapatinib combined with letrozole vs. letrozole alone for front line postmenopausal hormone receptor positive $(\mathrm{HR}+)$ metastatic breast cancer (MBC): first results from the EGF30008 Trial. San Antonio Breast Cancer Symposium abstract 46.

Johnston SR, Semiglazov VF, Manikhas GM, Spaeth D, Romieu G, Dodwell DJ, Wardley AM, Neven P, Bessems A, Park YC et al. 2008b A phase II, randomized, blinded study of the farnesyltransferase inhibitor tipifarnib combined with letrozole in the treatment of advanced breast cancer after antiestrogen therapy. Breast Cancer Research and Treatment 110 327-335.

Jones HE, Goddard L, Gee JM, Hiscox S, Rubini M, Barrow D, Knowlden JM, Williams S, Wakeling AE \& Nicholson RI 2004 Insulin-like growth factor-I receptor signalling and acquired resistance to gefitinib (ZD1839; Iressa) in human breast and prostate cancer cells. Endocrine-Related Cancer 11 793-814.

Karakas B, Bachman KE \& Park BH 2006 Mutation of the PIK3CA oncogene in human cancers. British Journal of Cancer 94 455-459.

Kelland LR, Smith V, Valenti M, Patterson L, Clarke PA, Detre S, End D, Howes AJ, Dowsett M, Workman P et al. 2001 Preclinical antitumor activity and pharmacodynamic studies with the farnesyl protein transferase inhibitor R115777 in human breast cancer. Clinical Cancer Research 7 3544-3550.
Khafagy R, Stephens T, Hart C, Ramani V, Brown M \& Clarke N 2004 In vitro effects of the prenyl transferase inhibitor AZD3409 on prostate cancer epithelial cells. Journal of Clinical Oncology 22 (Supplement 14S) abstract 4744.

Knowlden JM, Hutcheson IR, Jones HE, Madden T, Gee JM, Harper ME, Barrow D, Wakeling AE \& Nicholson RI 2003 Elevated levels of epidermal growth factor receptor/c-erbB2 heterodimers mediate an autocrine growth regulatory pathway in tamoxifen-resistant MCF-7 cells. Endocrinology 144 1032-1044.

Kowanetz M \& Ferrara N 2006 Vascular endothelial growth factor signaling pathways: therapeutic perspective. Clinical Cancer Research 12 5018-5022.

Krop IE, Miller KD, Zon RT, Isakoff S, Schneider CJ, Yu M, Johnson C, Vaughn LG, Shonukan OO \& Sledge GW 2008 A phase study of oral enzastaurin in patients with metastatic breast cancer previously treated with an anthracycline and a taxane-containing regimen: HOG BRE05-97. Journal of Clinical Oncology 26 (Supplement) abstract 1004.

Kumar R, Knick VB, Rudolph SK, Johnson JH, Crosby RM, Crouthamel MC, Hopper TM, Miller CG, Harrington LE, Onori JA et al. 2007 Pharmacokinetic-pharmacodynamic correlation from mouse to human with pazopanib, a multikinase angiogenesis inhibitor with potent antitumor and antiangiogenic activity. Molecular Cancer Therapeutics 6 2012-2021.

Larue L \& Bellacosa A 2005 Epithelial-mesenchymal transition in development and cancer: role of phosphatidylinositol $3^{\prime}$ kinase/AKT pathways. Oncogene 24 7443-7454.

Di Leo A, Gomez H, Aziz Z, Zvirbule Z, Arbushites M, Oliva CR, Koehler M, Williams LS, Dering J \& Finn RS 2007 Lapatinib (L) with paclitaxel compared to paclitaxel as first-line treatment for patients with metastatic breast cancer: a phase III randomized, double-blind study of 580 patients. Journal of Clinical Oncology 25 (Supplement 18S) abstract 1011.

Li X, Lewis MT, Huang J, Gutierrez C, Osborne CK, Wu MF, Hilsenbeck SG, Pavlick A, Zhang X, Chamness GC et al. 2008 Intrinsic resistance of tumorigenic breast cancer cells to chemotherapy. Journal of the National Cancer Institute 100 672-679.

Liu M, Bryant MS, Chen J, Lee S, Yaremko B, Lipari P, Malkowski M, Ferrari E, Nielsen L, Prioli N et al. 1998 Antitumor activity of SCH 66336, an orally bioavailable tricyclic inhibitor of farnesyl protein transferase, in human tumor xenograft models and wap-ras transgenic mice. Cancer Research 58 4947-4956.

Liu W, Bagaitkar J \& Watabe K 2007 Roles of AKT signal in breast cancer. Frontiers in Bioscience 12 4011-4019.

Lombardo LJ, Lee FY, Chen P, Norris D, Barrish JC, Behnia K, Castaneda S, Cornelius LA, Das J, Doweyko AM et al. 2004 Discovery of $N$-(2-chloro-6-methylphenyl)-2-(6-(4-(2-hydroxyethyl)- piperazin-1-yl)-2methylpyrimidin-4-ylamino)thiazole-5-carboxamide 
(BMS-354825), a dual Src/Abl kinase inhibitor with potent antitumor activity in preclinical assays. Journal of Medicinal Chemistry 47 6658-6661.

Lu CH, Wyszomierski SL, Tseng LM, Sun MH, Lan KH, Neal CL, Mills GB, Hortobagyi GN, Esteva FJ \& Yu D 2007 Preclinical testing of clinically applicable strategies for overcoming trastuzumab resistance caused by PTEN deficiency. Clinical Cancer Research 13 5883-5888.

Luo FR, Luo FR, Barrett Y, Ji P, Holly P, McCann E, Rhyne P, Clarke E, He K, Bleichardt E et al. 2006 Dasatinib (BMS-354825) pharmacokinetics correlate with pSRC pharmacodynamics in phase I studies of patients with cancer (CA180002, CA180003). Journal of Clinical Oncology 24 (abstr 3046).

Lyons JA, Silverman P, Remick S, Chen H, Leeming R, Shenk R, Fu P, Dumadag L, Escuro K \& Overmoyer B 2006 Toxicity results and early outcome data on a randomized phase II study of docetaxel $\{+/-\}$ bevacizumab for locally advanced, unresectable breast cancer. Journal of Clinical Oncology 24 (abstr 3049).

Maa MC, Leu TH, McCarley DJ, Schatzman RC \& Parsons SJ 1995 Potentiation of epidermal growth factor receptormediated oncogenesis by c-Src: implications for the etiology of multiple human cancers. PNAS 92 6981-6985.

Macaskill EJ, Bartlett JM, White S, Renshaw L, Campbell FM, Young O, Stumm M, Faratian D, Thomas JS, Barber MD et al. 2006 The mammalian target of rapamycin inhibitor RAD001 (everolimus) in postmenopausal women with early breast cancer: results of a phase II pre-operative trial. San Antonio Breast Cancer Symposium abstract 6092.

Mackay HJ \& Twelves CJ 2007 Targeting the protein kinase C family: are we there yet? Nature Reviews. Cancer 7 554-562.

Mackey JR, Kaufman B, Clemens M, Bapsy PP, Vaid A, Wardley A, Tjulandin S, Jahn M, Lehle M \& Jones A 2006 Trastuzumab prolongs progression-free survival in hormone-dependent and HER2-positive metastatic breast cancer. Breast Cancer Research and Treatment 100 abstract 3 .

Maiello MR, D’Alessio A, De Luca A, Carotenuto A, Rachiglio AM, Napolitano M, Cito L, Guzzo A \& Normanno N 2007 AZD3409 inhibits the growth of breast cancer cells with intrinsic resistance to the EGFR tyrosine kinase inhibitor gefitinib. Breast Cancer Research and Treatment 102 275-282.

De Maio E, Pacilio C, Gravina A, Morabito A, Di Rella F, Labonia V, Landi G, Nuzzo F, Rossi E, Silvestro P et al. 2007 Vinorelbine plus 3-weekly trastuzumab in metastatic breast cancer: a single-centre phase 2 trial. $B M C$ Cancer 750.

Margolin K, Gordon MS, Holmgren E, Gaudreault J, Novotny W, Fyfe G, Adelman D, Stalter S \& Breed J 2001 Phase $\mathrm{Ib}$ trial of intravenous recombinant humanized monoclonal antibody to vascular endothelial growth factor in combination with chemotherapy in patients with advanced cancer: pharmacologic and long-term safety data. Journal of Clinical Oncology 19 851-856.

Martin LA, Farmer I, Johnston SR, Ali S, Marshall C \& Dowsett M 2003 Enhanced estrogen receptor (ER) alpha, ERBB2, and MAPK signal transduction pathways operate during the adaptation of MCF-7 cells to long term estrogen deprivation. Journal of Biolgical Chemistry 278 30458-30468.

Martin LA, Head JE, Pancholi S, Salter J, Quinn E, Detre S, Kaye S, Howes A, Dowsett M \& Johnston SR 2007 The farnesyltransferase inhibitor R115777 (tipifarnib) in combination with tamoxifen acts synergistically to inhibit MCF-7 breast cancer cell proliferation and cell cycle progression in vitro and in vivo. Molecular Cancer Therapeutics 6 2458-2467.

Marty M, Cognetti F, Maraninchi D, Snyder R, Mauriac L, Tubiana-Hulin M, Chan S, Grimes D, Anton A, Lluch A et al. 2005 Randomized phase II trial of the efficacy and safety of trastuzumab combined with docetaxel in patients with human epidermal growth factor receptor 2-positive metastatic breast cancer administered as first-line treatment: the M77001 study group. Journal of Clinical Oncology 23 4265-4274.

Mayer I, Ganja N, Shyr Y, Muldowney N \& Arteaga CA 2006 A phase II trial of letrozole plus erlotinib in postmenopausal women with hormone-sensitive metastatic breast cancer: preliminary results of toxicities and correlative studiesI. Breast Cancer Research and Treatment 100 abstract 4052.

Messersmith WA, Krishnamurthi S, Hewes BA, Zacharchuk CM, Abbas R, Martins P, Dowling E, Volkert A, Martin E \& Daud AI 2007 Bosutinib (SKI-606), a dual Src/Abl tyrosine kinase inhibitor: preliminary results from a phase 1 study in patients with advanced malignant solid tumors. Journal of Clinical Oncology 25 (Supplement 18S) abstract 3552.

Miles D, Chan A, Romieu G, Dirix LY, Cortes J, Pivot X, Tomczak P, Taran T, Harbeck N \& Steger GG 2008 Randomized, double-blind, placebo-controlled, phase III study of bevacizumab with docetaxel or docetaxel with placebo as first-line therapy for patients with locally recurrent or metastatic breast cancer (mBC): AVADO. Journal of Clinical Oncology 26 (Supplement) abstract LBA1011.

Miller KD, Chap LI, Holmes FA, Cobleigh MA, Marcom PK, Fehrenbacher L, Dickler M, Overmoyer BA, Reimann JD, Sing AP et al. 2005a Randomized phase III trial of capecitabine compared with bevacizumab plus capecitabine in patients with previously treated metastatic breast cancer. Journal of Clinical Oncology 23 792-799.

Miller KD, Trigo JM, Wheeler C, Barge A, Rowbottom J, Sledge G \& Baselga JA 2005b A multicenter phase II trial of ZD6474, a vascular endothelial growth factor receptor2 and epidermal growth factor receptor tyrosine kinase inhibitor, in patients with previously treated metastatic breast cancer. Clinical Cancer Research 11 3369-3376. 
Miller K, Wang M, Gralow J, Dickler M, Cobleigh M, Perez EA, Shenkier T, Cella D \& Davidson NE 2007 Paclitaxel plus bevacizumab versus paclitaxel alone for metastatic breast cancer. New England Journal of Medicine 357 2666-2676.

von Minckwitz G, Jonat W, Fasching P, du Bois A, Kleeberg U, Luck HJ, Kettner E, Hilfrich J, Eiermann W, Torode $\mathrm{J}$ et al. 2005 A multicentre phase II study on gefitinib in taxane- and anthracycline-pretreated metastatic breast cancer. Breast Cancer Research and Treatment 89 165-172.

von Minckwitz G, du Bois A, Schmidt M, Maass N, Cufer T, de Jongh FE, Maartense E, Zielinski C, Kaufmann M, Bauer W et al. 2009 Trastuzumab beyond progression in human epidermal growth factor receptor 2-positive advanced breast cancer: a german breast group 26/breast international group 03-05 study. Journal of Clinical Oncology 27 1999-2006.

Mita M, de Bono J, Patnaik A, Ricart A, Berg K, Takimoto C, Rowinsky E, Tolcher A \& Beeram M 2005 A phase II and biologic correlative study investigating anastrozole in combination with gefitinib in post menopausal patients with estrogen receptor positive metastatic breast carcinoma who have previously failed hormonal therapy. Breast Cancer Research and Treatment 94 abstract 1117.

Moasser MM, Basso A, Averbuch SD \& Rosen N 2001 The tyrosine kinase inhibitor ZD1839 ("Iressa") inhibits HER2-driven signaling and suppresses the growth of HER2-overexpressing tumor cells. Cancer Research 61 7184-7188.

Modi S, D’Andrea G, Norton L, Yao TJ, Caravelli J, Rosen PP, Hudis C \& Seidman AD 2006 A phase I study of cetuximab/paclitaxel in patients with advanced-stage breast cancer. Clinical Breast Cancer 7 270-277.

Montemurro F, Donadio M, Clavarezza M, Redana S, Jacomuzzi ME, Valabrega G, Danese S, Vietti-Ramus G, Durando A, Venturini M et al. 2006 Outcome of patients with HER2-positive advanced breast cancer progressing during trastuzumab-based therapy. Oncologist 11 318-324.

Morabito A, De Maio E, Normanno N \& Perrone F $2006 a$ Tyrosine kinase inhibitors of vascular endothelial growth factor receptors in clinical trials: current status and future directions. Oncologist 11 753-764.

Morabito A, Longo R, Gattuso D, Carillio G, Massaccesi C, Mariani L, Bonginelli P, Amici S, De Sio L, Fanelli M et al. $2006 b$ Trastuzumab in combination with gemcitabine and vinorelbine as second-line therapy for HER2/neu overexpressing metastatic breast cancer. Oncology Reports 16 393-398.

Morabito A, Piccirillo MC, Falasconi F, De Feo G, Del Giudice A, Bryce J, Di Maio M, De Maio E, Normanno N \& Perrone F 2009 Vandetanib (ZD6474), a dual inhibitor of vascular endothelial growth factor receptor (VEGFR) and epidermal growth factor receptor (EGFR) tyrosine kinases: current status and future directions. Oncologist 14 378-390.
Moreno-Aspitia A, Hillman DW, Wiesenfeld M, Hobday TJ, Rowland KM, Northfelt DW, Tenner KS, Palmieri FM \& Perez EA 2006 BAY43-9006 as single oral agent in patients with metastatic breast cancer previously exposed to anthracycline and/or taxane. Journal of Clinical Oncology 24 (Supplement 18S) abstract 577.

Moulder SL, Yakes FM, Muthuswamy SK, Bianco R, Simpson JF \& Arteaga CL 2001 Epidermal growth factor receptor (HER1) tyrosine kinase inhibitor ZD1839 (Iressa) inhibits HER2/neu (erbB2)-overexpressing breast cancer cells in vitro and in vivo. Cancer Research 61 8887-8895.

Murray LJ, Abrams TJ, Long KR, Ngai TJ, Olson LM, Hong W, Keast PK, Brassard JA, O'Farrell AM, Cherrington JM et al. 2003 SU11248 inhibits tumor growth and CSF-1R-dependent osteolysis in an experimental breast cancer bone metastasis model. Clinical \& Experimental Metastasis 20 757-766.

Nahta R, Hung MC \& Esteva FJ 2004 The HER-2-targeting antibodies trastuzumab and pertuzumab synergistically inhibit the survival of breast cancer cells. Cancer Research 64 2343-2346.

Nanda R 2007 Targeting the human epidermal growth factor receptor 2 (HER2) in the treatment of breast cancer: recent advances and future directions. Reviews on Recent Clinical Trials 2 111-116.

Nicholson RI, Staka C, Boyns F, Hutcheson IR \& Gee JM 2004 Growth factor-driven mechanisms associated with resistance to estrogen deprivation in breast cancer: new opportunities for therapy. Endocrine-Related Cancer 11 623-641.

Normanno N, Bianco C, De Luca A \& Salomon DS 2001 The role of EGF-related peptides in tumor growth. Frontiers in Bioscience 6 D685-D707.

Normanno N, Campiglio M, De Luca A, Somenzi G, Maiello M, Ciardiello F, Gianni L, Salomon DS \& Menard S 2002 Cooperative inhibitory effect of ZD1839 (Iressa) in combination with trastuzumab (Herceptin) on human breast cancer cell growth. Annals of Oncology 13 65-72.

Normanno N, Bianco C, De Luca A, Maiello MR \& Salomon DS 2003 Target-based agents against ErbB receptors and their ligands: a novel approach to cancer treatment. Endocrine-Related Cancer 10 1-21.

Normanno N, Bianco C, Strizzi L, Mancino M, Maiello MR, De Luca A, Caponigro F \& Salomon DS 2005a The ErbB receptors and their ligands in cancer: an overview. Current Drug Targets 6 243-257.

Normanno N, De Luca A, Aldinucci D, Maiello MR, Mancino M, D'Antonio A, De Filippi R \& Pinto A $2005 b$ Gefitinib inhibits the ability of human bone marrow stromal cells to induce osteoclast differentiation: implications for the pathogenesis and treatment of bone metastasis. Endocrine-Related Cancer 12 $471-482$. 
Normanno N, De Luca A, Maiello MR, Mancino M, D’Antonio A, Macaluso M, Caponigro F \& Giordano A $2005 c$ Epidermal growth factor receptor (EGFR) tyrosine kinase inhibitors in breast cancer: current status and future development. Frontiers in Bioscience 10 2611-2617.

Normanno N, Di Maio M, De Maio E, De Luca A, de Matteis A, Giordano A \& Perrone F 2005d Mechanisms of endocrine resistance and novel therapeutic strategies in breast cancer. Endocrine-Related Cancer 12 721-747.

Normanno N, De Luca A, Maiello MR, Campiglio M, Napolitano M, Mancino M, Carotenuto A \& Viglietto G 2006 The MEK/MAPK pathway is involved in the resistance of breast cancer cells to the EGFR tyrosine kinase inhibitor gefitinib. Journal of Cellular Physiology 207 420-427.

Normanno N, Campiglio M, Maiello MR, De Luca A, Mancino M, Gallo M \& D'Alessio A 2008 Breast cancer cells with acquired resistance to the EGFR tyrosine kinase inhibitor gefitinib show persistent activation of MAPK signaling. Breast Cancer Research and Treatment 112 25-33.

O'Brian C, Vogel VG, Singletary SE \& Ward NE 1989 Elevated protein kinase $\mathrm{C}$ expression in human breast tumor biopsies relative to normal breast tissue. Cancer Research 49 3215-3217.

Olayioye MA, Neve RM, Lane HA \& Hynes NE 2000 The ErbB signaling network: receptor heterodimerization in development and cancer. EMBO Journal 19 3159-3167.

O'Regan RM \& Khuri FR 2004 Farnesyl transferase inhibitors: the next targeted therapies for breast cancer? Endocrine-Related Cancer 11 191-205.

Osborne K, Neven P, Dirix L, Mackey J, Robert J, Underhill C, Gutierrez C, Magill P \& Hargreaves L 2007 Randomized phase II study of gefitinib (IRESSA) or placebo in combination with tamoxifen in patients with hormone receptor positive metastatic breast cancer. San Antonio Breast Cancer Symposium abstract 2067.

O'Shaughnessy J, Weckstein DJ, Vukelja SJ, McIntyre K, Krekow L, Holmes FA, Asmar L \& Blum JL 2007 Preliminary results of a randomized phase II study of weekly irinotecan/carboplatin with or without cetuximab in patients with metastatic breast cancer. Breast Cancer Research and Treatment 106 S32.

O’Shaughnessy J, Blackwell KL, Burstein H, Storniolo AM, Sledge G, Baselga J, Koehler M, Laabs S, Florance A \& Roychowdhury D 2008 A randomized study of lapatinib alone or in combination with trastuzumab in heavily pretreated HER2 + metastatic breast cancer progressing on trasuzumab therapy. Journal of Clinical Oncology 26 (Supplement) abstract 1015.

Osoba D, Slamon DJ, Burchmore M \& Murphy M 2002 Effects on quality of life of combined trastuzumab and chemotherapy in women with metastatic breast cancer. Journal of Clinical Oncology 20 3106-3113.
Papaldo P, Fabi A, Ferretti G, Mottolese M, Cianciulli AM, Di Cocco B, Pino MS, Carlini P, Di Cosimo S, Sacchi I et al. 2006 A phase II study on metastatic breast cancer patients treated with weekly vinorelbine with or without trastuzumab according to HER2 expression: changing the natural history of HER2-positive disease. Annals of Oncology 17 630-636.

Pegram MD, Pienkowski T, Northfelt DW, Eiermann W, Patel R, Fumoleau P, Quan E, Crown J, Toppmeyer D, Smylie M et al. 2004 Results of two open-label, multicenter phase II studies of docetaxel, platinum salts, and trastuzumab in HER2-positive advanced breast cancer. Journal of the National Cancer Institute 96 759-769.

Peralba JM, DeGraffenried L, Friedrichs W, Fulcher L, Grunwald V, Weiss G \& Hidalgo M 2003 Pharmacodynamic evaluation of CCI-779, an inhibitor of mTOR, in cancer patients. Clinical Cancer Research 9 2887-2892.

Perez EA 2005 Further analysis of NCCTG-N9831. Slide presentation presented at the 45th Annual ASCO meeting, Orlando, FL, USA, May 13-17, 2005. Available at: http://www.asco.org/ASCOv2/MultiMedia/ Virtual + Meeting?\&vmview = vm_session_presentations_view\&confID $=34 \&$ sessionID $=934$

Perez EA, Byrne JA, Hammond IW, Rafi R, Martin AM, Berger MS, Zaks TZ, Oliva CR, Roychowdhury DF \& Stein SH 2006 Results of an analysis of cardiac function in 2,812 patients treated with lapatinib. Journal of Clinical Oncology 24 (Supplement 18S) abstract 583 .

Piccart-Gebhart MJ, Procter M, Leyland-Jones B, Goldhirsch A, Untch M, Smith I, Gianni L, Baselga J, Bell R, Jackisch C et al. 2005 Trastuzumab after adjuvant chemotherapy in HER2-positive breast cancer. New England Journal of Medicine 353 1659-1672.

Piechocki MP, Yoo GH, Dibbley SK \& Lonardo F 2007 Breast cancer expressing the activated HER2/neu is sensitive to gefitinib in vitro and in vivo and acquires resistance through a novel point mutation in the HER2/neu. Cancer Research 67 6825-6843.

Polychronis A, Sinnett HD, Hadjiminas D, Singhal H, Mansi JL, Shivapatham D, Shousha S, Jiang J, Peston D, Barrett N et al. 2005 Preoperative gefitinib versus gefitinib and anastrozole in postmenopausal patients with oestrogen-receptor positive and epidermal-growth-factorreceptor-positive primary breast cancer: a double-blind placebo-controlled phase II randomised trial. Lancet Oncology 6 383-391.

Reis-Filho JS \& Tutt AN 2008 Triple negative tumours: a critical review. Histopathology 52 108-118.

Robert N, Leyland-Jones B, Asmar L, Belt R, Ilegbodu D, Loesch D, Raju R, Valentine E, Sayre R, Cobleigh M et al. 2006 Randomized phase III study of trastuzumab, paclitaxel, and carboplatin compared with trastuzumab 
and paclitaxel in women with HER-2-overexpressing metastatic breast cancer. Journal of Clinical Oncology 24 2786-2792.

Robertson JFR, Gutteridge E, Cheung KL, Owers R, Koehler M, Hamilton L, Gee J \& Nicholson RI 2003 Gefitinib (ZD1839) is active in acquired tamoxifen (TAM)-resistant oestrogen receptor (ER)-positive and ER-negative breast cancer: results from a phase II study. Proceedings of the American Society of Clinical Oncology 22 abstract 23.

Romond EH, Perez EA, Bryant J, Suman VJ, Geyer CE Jr, Davidson NE, Tan-Chiu E, Martino S, Paik S, Kaufman PA et al. 2005 Trastuzumab plus adjuvant chemotherapy for operable HER2-positive breast cancer. New England Journal of Medicine 353 1673-1684.

Rugo HS, Herbst RS, Liu G, Park JW, Kies MS, Steinfeldt HM, Pithavala YK, Reich SD, Freddo JL \& Wilding G 2005 Phase I trial of the oral antiangiogenesis agent AG013736 in patients with advanced solid tumors: pharmacokinetic and clinical results. Journal of Clinical Oncology 23 5474-5483.

Rugo HS, Stopeck A, Joy AA, Chan S, Verma S, Lluch A, Liau KF, Kim S, Bycott P \& Soulieres D 2007 A randomized, double-blind phase II study of the oral tyrosine kinase inhibitor (TKI) axitinib (AG-013736) in combination with docetaxel (DOC) compared to DOC plus placebo (PL) in metastatic breast cancer (MBC). Journal of Clinical Oncology 25 (Supplement 18S) abstract 1003.

Rusnak DW, Affleck K, Cockerill SG, Stubberfield C, Harris R, Page M, Smith KJ, Guntrip SB, Carter MC, Shaw RJ et al. 2001 The characterization of novel, dual ErbB-2/EGFR, tyrosine kinase inhibitors: potential therapy for cancer. Cancer Research 61 7196-7203.

Salomon DS, Brandt R, Ciardiello F \& Normanno N 1995 Epidermal growth factor-related peptides and their receptors in human malignancies. Critical Reviews in Oncology/Hematology 19 183-232.

Scaltriti M, Rojo F, Ocana A, Anido J, Guzman M, Cortes J, Di Cosimo S, Matias-Guiu X, Ramon y Cajal S, Arribas J et al. 2007 Expression of p95HER2, a truncated form of the HER2 receptor, and response to anti-HER2 therapies in breast cancer. Journal of the National Cancer Institute 99 628-638.

Schaefer G, Shao L, Totpal K \& Akita RW 2007 Erlotinib directly inhibits HER2 kinase activation and downstream signaling events in intact cells lacking epidermal growth factor receptor expression. Cancer Research 67 1228-1238.

Schaller G, Fuchs I, Gonsch T, Weber J, Kleine-Tebbe A, Klare P, Hindenburg HJ, Lakner V, Hinke A \& Bangemann N 2007 Phase II study of capecitabine plus trastuzumab in human epidermal growth factor receptor 2 overexpressing metastatic breast cancer pretreated with anthracyclines or taxanes. Journal of Clinical Oncology 25 3246-3250.
Schneider BP \& Miller KD 2005 Angiogenesis of breast cancer. Journal of Clinical Oncology 23 1782-1790.

Sergina NV, Rausch M, Wang D, Blair J, Hann B, Shokat KM \& Moasser MM 2007 Escape from HER-family tyrosine kinase inhibitor therapy by the kinase-inactive HER3. Nature 445 437-441.

Sinclair CS, Rowley M, Naderi A \& Couch FJ 2003 The 17 q23 amplicon and breast cancer. Breast Cancer Research and Treatment 78 313-322.

Slamon DJ, Leyland-Jones B, Shak S, Fuchs H, Paton V, Bajamonde A, Fleming T, Eiermann W, Wolter J, Pegram M et al. 2001 Use of chemotherapy plus a monoclonal antibody against HER2 for metastatic breast cancer that overexpresses HER2. New England Journal of Medicine 344 783-792.

Slamon D, Eiermann W, Robert N, Pienkowski T, Martin M, Pawlicki M, Chan A, Smylie M, Liu M, Falkson C et al. 2006 BCIRG 006: 2nd interim analysis phase III randomized trial comparing doxorubicin and cyclophosphamide followed by docetaxel $(\mathrm{AC} \rightarrow \mathrm{T})$ with doxorubicin and cyclophosphamide followed by docetaxel and trastuzumab $(\mathrm{AC} \rightarrow \mathrm{TH})$ with docetaxel, carboplatin and trastuzumab $(\mathrm{TCH})$ in Her2neu positive early breast cancer patients. San Antonio Breast Cancer Symposium abstract 52.

Slamon D, Gomez HL, Kabbinavar FF, Amit O, Richie M, Pandite L \& Goodman V 2008 Randomized study of pazopanib + lapatinib vs. lapatinib alone in patients with HER2- positive advanced or metastatic breast cancer. Journal of Clinical Oncology 26 (Supplement) abstract 1016.

Sledge GW Jr \& Gokmen-Polar Y 2006 Protein kinase C-beta as a therapeutic target in breast cancer. Seminars in Oncology 33 S15-S18.

Smith I, Procter M, Gelber RD, Guillaume S, Feyereislova A, Dowsett M, Goldhirsch A, Untch M, Mariani G, Baselga J et al. 2007a 2-year follow-up of trastuzumab after adjuvant chemotherapy in HER2-positive breast cancer: a randomised controlled trial. Lancet 369 29-36.

Smith IE, Walsh G, Skene A, Llombart A, Mayordomo JI, Detre S, Salter J, Clark E, Magill P \& Dowsett M 2007b A phase II placebo-controlled trial of neoadjuvant anastrozole alone or with gefitinib in early breast cancer. Journal of Clinical Oncology 25 3816-3822.

Sorlie T, Perou CM, Tibshirani R, Aas T, Geisler S, Johnsen H, Hastie T, Eisen MB, van de Rijn M, Jeffrey SS et al. 2001 Gene expression patterns of breast carcinomas distinguish tumor subclasses with clinical implications. PNAS 98 10869-10874.

Spector NL, Xia W, Burris H III, Hurwitz H, Dees EC, Dowlati A, O'Neil B, Overmoyer B, Marcom PK, Blackwell KL et al. 2005 Study of the biologic effects of lapatinib, a reversible inhibitor of ErbB1 and ErbB2 tyrosine kinases, on tumor growth and survival pathways in patients with advanced malignancies. Journal of Clinical Oncology 23 2502-2512. 
Spector NL, Blackwell K, Hurley J, Harris JL, Lombardi D, Bacus S, Ahmed SB, Boussen H, Frikha M \& Ayed FB 2006 EGF103009, a phase II trial of lapatinib monotherapy in patients with relapsed/refractory inflammatory breast cancer (IBC): clinical activity and biologic predictors of response. Journal of Clinical Oncology 24 (Supplement 18S) abstract 502.

Spielmann M, Roché H, Humblet Y, Delozier T, Bourgeois H, Serin D, Romieu G, Canon JL, Monnier A, Piot G et al. 2007 3-year follow-up of trastuzumab following adjuvant chemotherapy in node positive HER2-positive breast cancer patients: results of the PACS-04 trial. San Antonio Breast Cancer Symposium abstract 72.

Stephens TC, Wardleworth MJ, Matusiak ZS, Ashton SE, Hancox UJ, Bate M, Ferguson R \& Boyle T 2003 AZD3409, a novel, oral, prenyl transferase inhibitor with promising preclinical antitumour activity. Proceedings of the American Association for Cancer Research 44970.

Storniolo AM, Koehler M, Preston A, Rappold E, Byrne J \& Ewer MS 2007 Cardiac safety in patients (pts) with metastatic breast cancer (MBC) treated with lapatinib (L) and trastuzumab (TRA). Journal of Clinical Oncology $\mathbf{2 5}$ (Supplement 18S) abstract 514.

Tabernero J, Cervantes A, Hoekman K, Hurwitz HI, Jodrell DI, Hamberg P, Stuart M, Green TP, Iacona RB \& Baselga J 2007 Phase I study of AZD0530, an oral potent inhibitor of Src kinase: first demonstration of inhibition of Src activity in human cancers. Journal of Clinical Oncology 25 (Supplement 18S) abstract 3520.

Tabernero J, Rojo F, Calvo E, Burris H, Judson I, Hazell K, Martinelli E, Ramon y Cajal S, Jones S, Vidal L et al. 2008 Dose- and schedule-dependent inhibition of the mammalian target of rapamycin pathway with everolimus: a phase I tumor pharmacodynamic study in patients with advanced solid tumors. Journal of Clinical Oncology 26 1603-1610.

Tamura T, Minami H, Yamada Y, Yamamoto N, Shimoyama T, Murakami H, Horiike A, Fujisaka Y, Shinkai T, Tahara M et al. 2006 A phase I dose-escalation study of ZD6474 in Japanese patients with solid, malignant tumors. Journal of Thoracic Oncology 1 1002-1009.

Tripathy D, Slamon DJ, Cobleigh M, Arnold A, Saleh M, Mortimer JE, Murphy M \& Stewart SJ 2004 Safety of treatment of metastatic breast cancer with trastuzumab beyond disease progression. Journal of Clinical Oncology 22 1063-1070.

Vivanco I \& Sawyers CL 2002 The phosphatidylinositol 3-kinase AKT pathway in human cancer. Nature Reviews. Cancer 2 489-501.

Vogel CL, Cobleigh MA, Tripathy D, Gutheil JC, Harris LN, Fehrenbacher L, Slamon DJ, Murphy M, Novotny WF, Burchmore M et al. 2002 Efficacy and safety of trastuzumab as a single agent in first-line treatment of HER2-overexpressing metastatic breast cancer. Journal of Clinical Oncology 20 719-726.

Wakeling AE 2005 Inhibitors of growth factor signalling. Endocrine-Related Cancer 12 S183-S187.

Wedam SB, Low JA, Yang SX, Chow CK, Choyke P, Danforth D, Hewitt SM, Berman A, Steinberg SM, Liewehr DJ et al. 2006 Antiangiogenic and antitumor effects of bevacizumab in patients with inflammatory and locally advanced breast cancer. Journal of Clinical Oncology 24 769-777.

Wedge SR, Ogilvie DJ, Dukes M, Kendrew J, Chester R, Jackson JA, Boffey SJ, Valentine PJ, Curwen JO, Musgrove HL et al. 2002 ZD6474 inhibits vascular endothelial growth factor signaling, angiogenesis, and tumor growth following oral administration. Cancer Research 62 4645-4655.

Wilhelm SM, Carter C, Tang L, Wilkie D, McNabola A, Rong $\mathrm{H}$, Chen $\mathrm{C}$, Zhang X, Vincent P, McHugh M et al. 2004 BAY 43-9006 exhibits broad spectrum oral antitumor activity and targets the RAF/MEK/ERK pathway and receptor tyrosine kinases involved in tumor progression and angiogenesis. Cancer Research 64 7099-7109.

Wiseman SM, Makretsov N, Nielsen TO, Gilks B, Yorida E, Cheang M, Turbin D, Gelmon K \& Huntsman DG 2005 Coexpression of the type 1 growth factor receptor family members HER-1, HER-2, and HER-3 has a synergistic negative prognostic effect on breast carcinoma survival. Cancer 103 1770-1777.

Xia W, Bacus S, Hegde P, Husain I, Strum J, Liu L, Paulazzo G, Lyass L, Trusk P, Hill J et al. 2006 A model of acquired autoresistance to a potent ErbB2 tyrosine kinase inhibitor and a therapeutic strategy to prevent its onset in breast cancer. PNAS $\mathbf{1 0 3}$ 7795-7800.

Yeatman TJ 2004 A renaissance for SRC. Nature Reviews. Cancer 4 470-480.

Yeh TC, Marsh V, Bernat BA, Ballard J, Colwell H, Evans RJ, Parry J, Smith D, Brandhuber BJ, Gross S et al. 2007 Biological characterization of ARRY-142886 (AZD6244), a potent, highly selective mitogen-activated protein kinase kinase 1/2 inhibitor. Clinical Cancer Research 13 1576-1583.

Yu K, Toral-Barza L, Discafani C, Zhang WG, Skotnicki J, Frost P \& Gibbons JJ 2001 mTOR, a novel target in breast cancer: the effect of CCI-779, an mTOR inhibitor, in preclinical models of breast cancer. Endocrine-Related Cancer 8 249-258.

Zhang M \& Rosen JM 2006 Stem cells in the etiology and treatment of cancer. Current Opinion in Genetics \& Development 1660. 